\title{
Flow Patterns and Heat Transfer for Flow Boiling in Small to Micro Diameter Tubes
}

\author{
T.G. Karayiannis ${ }^{1}$, D. Shiferaw ${ }^{1}$, D.B.R. Kenning ${ }^{1}$ and V. V. Wadekar ${ }^{2}$ \\ ${ }^{1}$ Brunel University, School of Engineering and Design, West London, Uxbridge, \\ Middlesex, UB8 3PH, UK, tassos.karayiannis@ brunel.ac.uk \\ ${ }^{2}$ HTFS, Aspen Technology Ltd, Reading, UK
}

\begin{abstract}
An overview of the recent developments in the study of flow patterns and boiling heat transfer in small to micro diameter tubes is presented. The latest results of a long-term study of flow boiling of R134a in five vertical stainless steel tubes of internal diameter 4.26, 2.88, 2.01, 1.1 and $0.52 \mathrm{~mm}$ are then discussed. During these experiments, the mass flux was varied from 100 to $700 \mathrm{~kg} / \mathrm{m}^{2} \mathrm{~s}$ and the heat flux from as low as 1.6 to $135 \mathrm{~kW} / \mathrm{m}^{2}$. Five different pressures were studied, namely 6,8 , 10, 12 and 14 bar. The flow regimes were observed at a glass section located directly at the exit of the heated test section. The range of diameters was chosen to investigate thresholds for macro, small or micro tube characteristics. The heat transfer coefficients in tubes ranging from $4.26 \mathrm{~mm}$ down to $1.1 \mathrm{~mm}$ increased with heat flux and system pressure, but did not change with vapour quality for low quality values. At higher quality, the heat transfer coefficients decreased with quality, indicating local dryout. There was no significant difference between the characteristics and magnitude of the heat transfer coefficients in the $4.26 \mathrm{~mm}$ and $2.88 \mathrm{~mm}$ tubes but the coefficients in the 2.01 and $1.1 \mathrm{~mm}$ tube higher. The heat transfer results suggested that a tube size of about $2 \mathrm{~mm}$ might be considered as a critical diameter to distinguish small and conventional tubes, This is consistent with an earlier study of flow patterns, in which confined bubble flow was observed only in the 2.01 and $1.1 \mathrm{~mm}$ tubes. Further differences have now been observed in the $0.52 \mathrm{~mm}$ tube: ring flow appeared over a significant range of quality/heat flux and dispersed flow was not observed. The heat transfer characteristics were also different from those in the larger tubes. The data fell into two groups that exhibited different influences of heat flux below and above a heat flux threshold. These differences, both in flow patterns and heat transfer, indicate a possible second change from small to micro behaviour at diameters less than 1 mm for R134a.
\end{abstract}

\section{INTRODUCTION}

Modelling and design of micro-devices of high thermal performance, including electronic chips and other systems containing compact and ultra-compact heat exchangers, require a fundamental understanding of thermal transport phenomena for the ultra-compact systems. In this emerging area of great practical interest, systematically measured boiling heat transfer data are required to understand the mechanisms of flow boiling in small to micro diameter passages.

\section{Channel Size Classification}

Identifying the channel diameter threshold, below which the macroscale heat transfer phenomena do not fully apply, is important in validating and developing predictive methods for the thermal-hydraulic performance of small to microscale channels. However, there is no clear and common agreement on the definition and classification criterion for the size ranges in small/mini/microchannel two-phase flow study. One reason could be the lack of comprehensive heat transfer data covering a wide range of channel diameters. Mehandale et al. (2000) defined channel size ranges as follows: microchannel $(1-100$ $\mu \mathrm{m})$, mesochannel $(100 \mu \mathrm{m}-1 \mathrm{~mm})$, macrochannel $(1-6$ $\mathrm{mm})$, conventional $\left(\mathrm{d}_{\mathrm{h}}>6 \mathrm{~mm}\right)$. Kandlikar and Grande (2003) suggested the classification of microscale by hydraulic diameter, given as: conventional channels $\left(\mathrm{d}_{\mathrm{h}} \geq 3 \mathrm{~mm}\right)$, minichannels $\left(200 \mu \mathrm{m} \leq \mathrm{d}_{\mathrm{h}}<3 \mathrm{~mm}\right)$ and microchannels $(10 \mu \mathrm{m}$ $\left.\leq \mathrm{d}_{\mathrm{h}}<200 \mu \mathrm{m}\right)$. These methods based only on size do not consider the physical mechanisms and the variation of fluid properties with pressure. The absence of stratified flow in horizontal microchannels, and hence the fact that the orientation of the channel has virtually no effect on two phase flow patterns, indicates the predominance of surface tension force over gravity. Consequently, a number of attempts to define macro-micro transition have used surface tension force as a base to formulate a non-dimensional criterion. These include Eotvös number $($ Eö $>1)$ recommended by Brauner and Maolem-Maron (1992] and confinement number $(C o=0.5)$ by Cornwell and Kew (1993). Thome (2004) in his review of boiling in microchannels indicated the importance of considering the effect of channel size on the physical mechanisms and discussed the use of bubble departure diameter as a preliminary criterion. He also mentioned the effects of shear on bubble departure diameter and the effect of reduced pressure on bubble size that should be considered in addition to surface tension forces. A comprehensive definition for normal and small size tubes is required that considers all the fundamental phenomena, based on experimental data for a wide range of conditions. The research presented here addressed this requirement by systematic measurements of 
flow boiling of R134a over wide ranges of pressures, flow rates and heat fluxes in five tubes with diameters ranging from 4.26 to $0.52 \mathrm{~mm}$. This choice of size range was based on an initial assessment using the confinement number proposed by Cornwell and Kew (1993).

\section{Flow Patterns}

Flow pattern studies in small/micro tubes have clearly shown that there is a considerable difference in the flow pattern characteristics compared with conventional size channels. These include the predominance of surface tension force over gravity, the absence of stratified flow pattern in horizontal channels and the appearance of additional flow patterns that are not common in normal diameter tubes. In the past some researchers have proposed several flow pattern classes, probably more than is necessary for modelling. Although there are arguments on the classification of flow patterns, the most commonly identified flow patterns so far are bubbly flow, slug flow, churn flow and annular flow. Barnea et al. (1983) classified the flow patterns as dispersed bubble, elongated bubble, slug, churn and annular. Elongated bubble, slug and churn were considered as intermittent flow. Dispersed flow and elongated bubble were replaced by bubbly flow in the Mishima and Hibiki (1996) classification. Kew and Cornwell (1997) experimentally observed flow regimes during their flow boiling tests in small diameter channels using R141b, and proposed only three distinct flow regimes. They defined the flow patterns as isolated bubble flow, confined bubble flow and annular-slug flow. Identification of flow patterns is subjected to uncertainty, which is not straightforward to quantify and can also be significantly influenced by the experimental technique used. Besides, the transition from one flow pattern to another may be a gradual rather an abrupt transition, as is often reported. Hence, flow patterns may possess characteristics of more than one flow pattern during transition. Chen et al (2006) reported the results of a detailed study of flow visualization experiments with R134a for a pressure range of 6-14 bar and tube diameter from 1.1, 2.01, 2.88 and $4.26 \mathrm{~mm}$ with the same test rig as the present one. The typical flow patterns observed in the four tubes are presented in Figure 1. They included: dispersed flow, bubbly flow, confined flow, slug flow, churn flow, annular flow and mist flow. The flow patterns in the 2.88 and $4.26 \mathrm{~mm}$ tubes exhibit characteristics found in large tubes. The flow patterns in the $2.01 \mathrm{~mm}$ tube demonstrate some "small tube characteristics", e.g. the appearance of confined bubble flow at the lowest pressure of 6 bar and slimmer vapour slug, thinner liquid film as well as a less chaotic vapour-liquid interface in churn flow. Confined flow was observed at all pressures when the diameter was reduced to $1.1 \mathrm{~mm}$, indicating that the $2.01 \mathrm{~mm}$ diameter tube can be a first threshold distinguishing traditional and small size tubes.

Studies of even smaller diameter tubes are described below. Serizawa et al. (2002) studied two phase flow in microchannels and reported the visualization results for airwater and steam-water flows in circular tube of 20,25 and 100 $\mu \mathrm{m}$ and $50 \mu \mathrm{m}$ internal diameter, respectively. They found several additional features to those observed in small diameter tubes. For air-water two phase flow in a $25 \mu \mathrm{m}$ silica tube the special flow pattern features found included liquid ring flow and liquid lump flow. The liquid ring flow was described as the appearance of a symmetrical liquid ring with long gas slugs passing in the middle. They hypothesized that the liquid ring flow could develop from slug flow when the gas slug velocity is too high and the liquid slug is too short to form a stable liquid bridge between consecutive gas slugs. At this condition, liquid lump flow appeared with further increases in the gas flow rate. According to Serizawa et al., "the high-speed core gas entrains the liquid phase and liquid lumps are sliding on the wall". Experiments using the same fluid but in a $100 \mu \mathrm{m}$ quartz tube gave similar results as for the $25 \mu \mathrm{m}$ silicon tubes except that small liquid droplets in gas slug flow were sticking on the tube wall, indicating the absence of a liquid film at these locations between the slug and the wall. Stable liquid ring flow and liquid lump flows were also reported for the $100 \mu \mathrm{m}$ tube. Similar flow patterns to those of air-water flow in the $25 \mu \mathrm{m}$ silica tube were observed in the case of steam-water flow in a $50 \mu \mathrm{m}$ silica tube, the only difference being the absence of liquid lump flow, which, according to Serizawa et al., was not a main flow but transition type flow. However, liquid ring flow was still found, which may indicate that the difference in the method of forming the two phase flow, i.e. boiling or adiabatic mixing of air-water, seems to have no considerable effect, at least for these sizes.

Kawahara et al. (2002) studied two phase flow characteristics of nitrogen and de-ionized water in a $100 \mu \mathrm{m}$ diameter tube made of fused silica, and reported the absence of bubbly and churn flow as one of the differences between their results and results for larger diameter tubes. In addition they reported the existence of liquid-ring flow and serpentine-like flow. Recently, Xiong and Chung (2007) studied experimentally adiabatic gas-liquid flow patterns using nitrogen and water in rectangular microchannels with hydraulic diameter of $0.209,0.412$ and $0.622 \mathrm{~mm}$. They observed four different flow patterns: bubbly, slug flow, slug-ring flow (liquid-ring flow), dispersed-churn flow, and annular flow in the 0.412 and $0.622 \mathrm{~mm}$ microchannels. The bubbly-slug flow developed to fully slug flow. They reported that dispersed and churn flows were absent in the $0.209 \mathrm{~mm}$ channel.

\section{Effect of Diameter on Transition Boundaries}

The effect of tube diameter on flow pattern transition boundaries was also studied by various researchers. Damianides and Westwater (1988) studied the flow regimes in horizontal tubes of 1 to $5 \mathrm{~mm}$ inside diameters using air-water. They reported that reducing the tube diameter shifted the transition boundaries between intermittent-dispersed bubbly and intermittent-annular flow towards lower liquid velocity and higher gas velocity respectively. Also, they did not observe stratified flow regime inside the $1 \mathrm{~mm}$ diameter tube. In the study of air-water flow patterns in tubes of 0.5 to $4.0 \mathrm{~mm}$ inside diameter, for vertical flow, Lin et al. (1998) observed that decreasing the tube diameter shifted the slug-churn and churn-annular transition boundaries towards lower vapour velocity. 

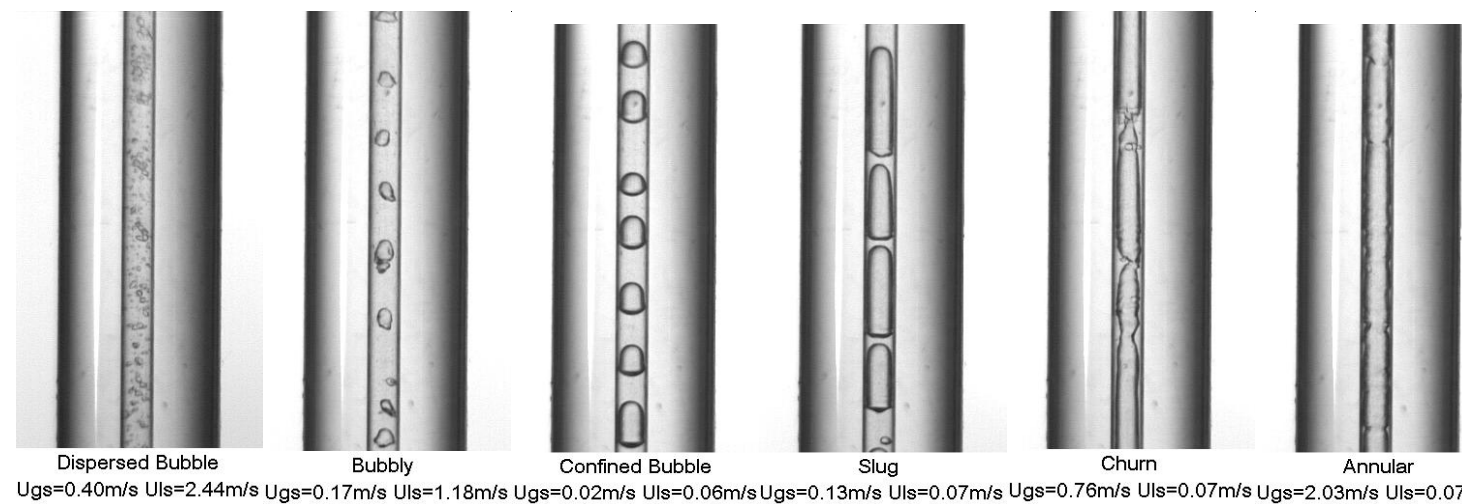

(a)

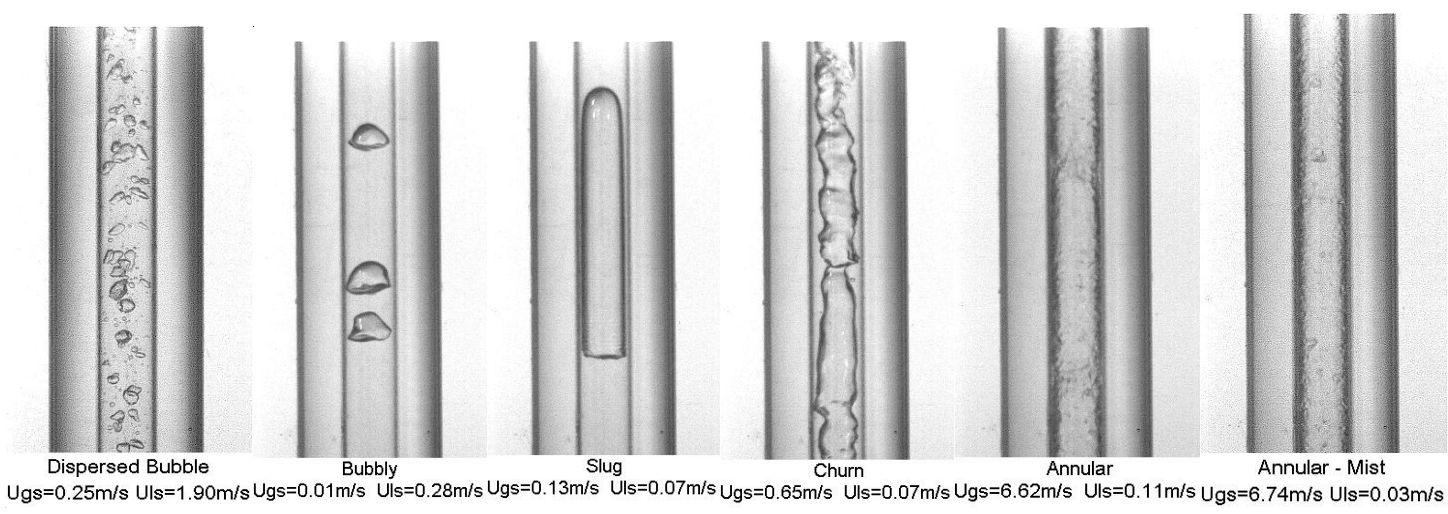

(b)
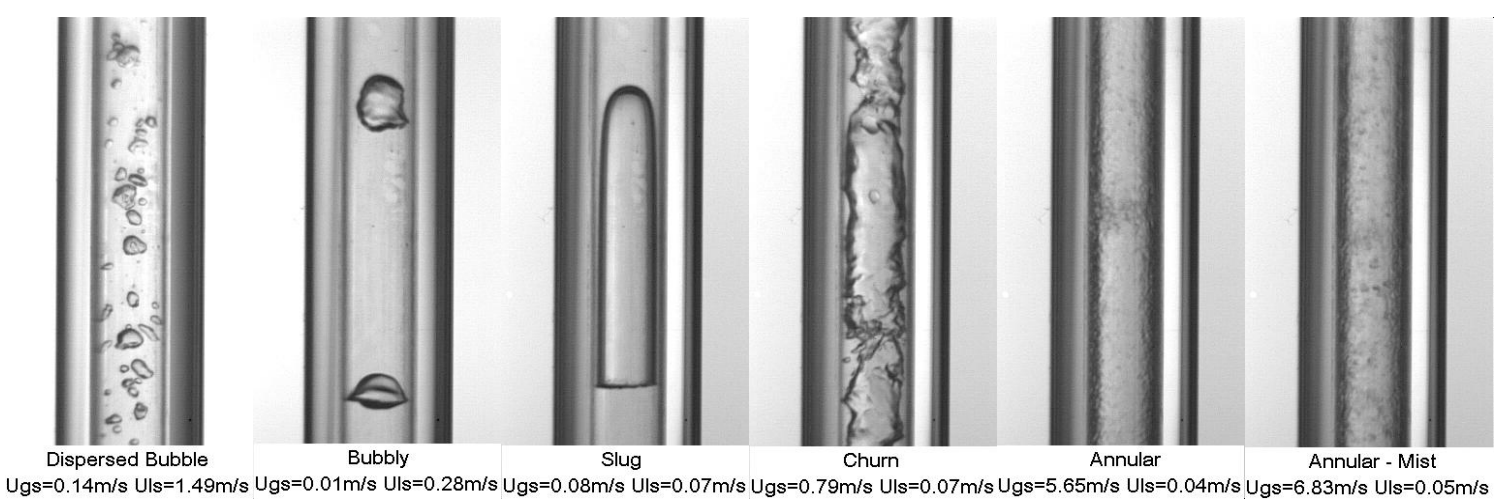

Ugs $=0.14 \mathrm{~m} / \mathrm{s}$ Uls $=1.49 \mathrm{~m} / \mathrm{s}$ Ugs $=0.01 \mathrm{~m} / \mathrm{s}$ Uls $=0.28 \mathrm{~m} / \mathrm{s}$ Ugs $=0.08 \mathrm{~m} / \mathrm{s}$ Uls $=0.07 \mathrm{~m} / \mathrm{s}$ Ugs $=0.79 \mathrm{~m} / \mathrm{s}$ Uls $=0.07 \mathrm{~m} / \mathrm{s} U g s=5.65 \mathrm{~m} / \mathrm{s}$ Uls $=0.04 \mathrm{~m} / \mathrm{s} \cup \mathrm{gs}=6.83 \mathrm{~m} / \mathrm{s}$ Uls $=0.05 \mathrm{~m} / \mathrm{s}$

(c)
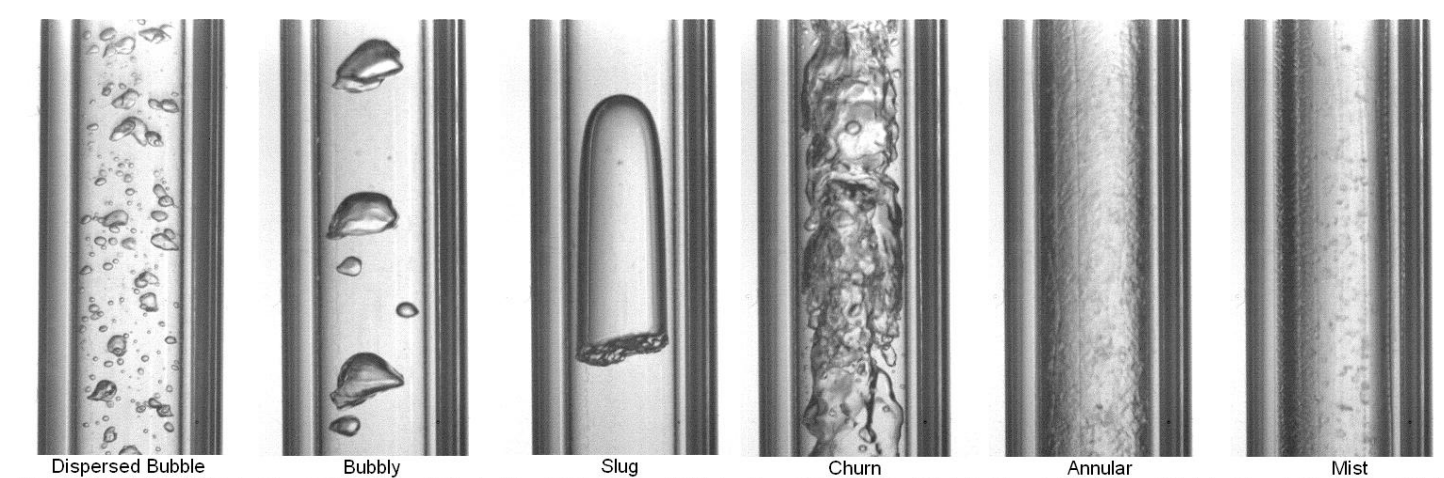

Ugs $=0.11 \mathrm{~m} / \mathrm{s}$ Uls $=1.19 \mathrm{~m} / \mathrm{s}$ Ugs $=0.01 \mathrm{~m} / \mathrm{s}$ Uls $=0.28 \mathrm{~m} / \mathrm{s}$ Ugs $=0.05 \mathrm{~m} / \mathrm{s}$ Uls $=0.07 \mathrm{~m} / \mathrm{s}$ Ugs $=0.67 \mathrm{~m} / \mathrm{s}$ Uls $=0.07 \mathrm{~m} / \mathrm{s}$ Ugs $=6.18 \mathrm{~m} / \mathrm{s}$ Uls $=0.07 \mathrm{~m} / \mathrm{s}$ Ugs $=8.84 \mathrm{~m} / \mathrm{s}$ Uls $=0.07 \mathrm{~m} / \mathrm{s}$

(d)

Figure 1. Flow patterns for R134a at 10 bar pressure: (a) $\mathrm{d}=1.10 \mathrm{~mm}$, (b) $\mathrm{d}=2.01 \mathrm{~mm}$, (c) $\mathrm{d}=2.88 \mathrm{~mm}$, (d) $\mathrm{d}=4.26 \mathrm{~mm}$, Chen et al. (2006) 
Recently, Chen et al. (2006) noted that the diameter influences the transition boundaries of dispersed bubblebubbly, slug-churn and churn-annular flow. Also, the slugchurn and churn-annular boundaries are weakly dependent on superficial liquid velocity and strongly dependent on superficial vapour velocity. There seems to be no effect of diameter at the boundaries of dispersed bubble-churn and bubbly-slug flow. The flow pattern transition data of Chen et al. are plotted on a mass flux versus quality graph in Figure 2 for pressures of 6 and 8 bar. As shown in the figure, when the diameter is reduced, the slug/churn and churn/annular transition lines shift towards higher quality. The change is more pronounced for moderate and low mass fluxes. There is no obvious effect on the bubbly/slug transition line. The flow regime boundaries are shifted to significantly lower qualities as the mass flux increases. At higher quality, the transition lines for different tubes merge into a single line. Chen et al. reported that the Weber number may be the appropriate parameter to deduce general correlations to predict the transition boundaries that include the effect of diameter.

Recently, new correlations for transition of non-adiabatic flow patterns were introduced by Revellin and Thome (2007). They identified three main flow patterns named as: a) the isolated bubble regime that includes bubbly flow and short slugs; in this regime coalescence is not significant, b) coalescing bubble regime, where slug flow is the main flow with some of the bubbles coalescence together to form a longer slug and c) annular regime. According to their observations, churn flow is a transition from coalescing bubble to annular flow, and it is considered as indication of the end of coalescing bubble flow. The flow pattern maps were plotted as mass flux versus quality graphs. Revellin and Thome proposed flow pattern transition correlations, which give the quality at which the transition occurs. For the transition from the isolated bubble to the coalescing bubble regime, their correlation contained the Reynolds, Boiling and Weber numbers, Eq. (1). A similar correlation for the transition from the coalescing bubble to the annular regime contained only the Reynolds number and the Weber number, Eq. (2).

$$
\begin{aligned}
& x=0.763 \cdot\left(\mathrm{Re}_{l o}^{\mathrm{Bo}} / \mathrm{We}{ }_{g o}\right)^{0.41} \\
& x=0.00014 \cdot\left(\operatorname{Re}_{l o}\right)^{\mathrm{N} 47} \cdot \mathrm{We}_{l o}^{-1.23}
\end{aligned}
$$

According to Eq. (1), the transition from isolated bubble to slug is independent of tube diameter, which is confirmed by the present results of Figure 2 (bubbly to slug flow). However, the transition from coalescing bubble to annular flow regime, which is equivalent to churn to annular transition, shifts to lower quality with decreasing diameter. This is contrary to the results of Chen et al. (2006) and could be due to the fact that the correlation was developed using tests with a single tube diameter rather than a range of tube diameters. For instance, at a mass flux of $400 \mathrm{~kg} / \mathrm{m}^{2} \mathrm{~s}$ and pressure of $8 \mathrm{bar}$, the transition qualities for the 2.01 and $1.10 \mathrm{~mm}$ tubes are $x=0.38$ and $x=0.32$, respectively. From the experimental results of Chen et al. (2006), shown in Figure 2 (b), the corresponding values are 0.22 and 0.24 , respectively.

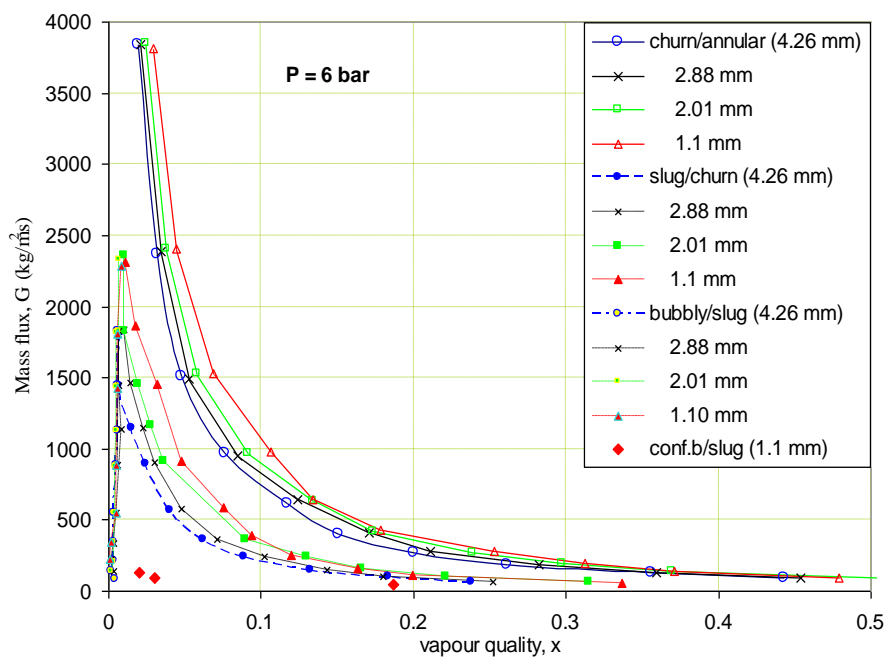

(a)

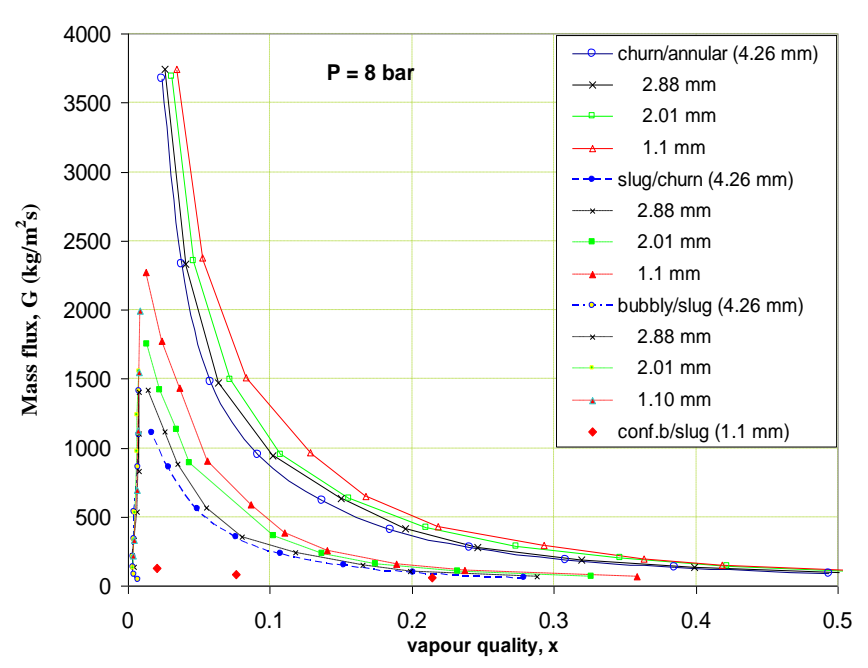

(b)

Figure 2. Flow patter transition boundary lines for the four tubes (Chen et al. 2006 data): (a) 6 bar (b) 8 bar pressure.

From the above review, it appears that small diameter tubes exhibit different flow pattern characteristics from those for large diameter tubes, e.g. the appearance of confined flow at about $2 \mathrm{~mm}$ for R134a, which indicates a threshold for change from large to small diameter. For the same fluid the Cornwell and Kew (1993) criterion gives a critical diameter of $1.7 \mathrm{~mm}$ for $\mathrm{P}=6$ bar pressure. Flow pattern studies for even smaller tubes (near or less than $1 \mathrm{~mm}$ ) revealed the existence of a number of different flow pattern types, e.g. ring flow, lump liquid flow, which have not been found in larger diameter tubes. This is indicative of a possible further change in flow patterns and hence in thermal characteristics at these even smaller diameters. This is discussed later in the paper in light of the recent results from our own investigations.

\section{Heat Transfer}

Nucleate boiling, forced convection and a combination of both are the main mechanisms often reported in the literature for flow boiling heat transfer. These have also been adopted in identifying the heat transfer mechanism in small diameter tubes and microchannels although different conclusions have 
been drawn by researchers as to their prevalence. Some researchers concluded that nucleate boiling is the dominant heat transfer mechanism when it was observed that the heat transfer coefficient is more or less independent of vapour quality and mass flux, while it is strongly dependent on heat flux, e.g. Lazarek and Black (1982), Wambsganss et al. (1993), Tran et al. (1996), Bao et al. (2000), Yu et al. (2002), Fujita (2002). On the other hand, some experimental studies have also reported an effect of the mass velocity and vapour quality but not of the heat flux on the heat transfer coefficient. The interpretation given to this is that forced convective boiling is the dominant heat transfer mechanism, e.g. Carey et al. (1992), Oh et al. (1998), Lee and Lee (2001), Qu and Mudawar (2003). Some researchers reported a combined effect of both mechanisms, i.e. nucleate boiling at low quality and forced convective boiling at high quality region in a similar way as that observed in large diameter tubes, e.g. Kuznestov and Shamirzaev (1999), Lin et al. (2001), Sumith et al. (2003), Saitoh et al. (2005). However, it is worth noting here that macroscale boiling heat transfer correlations and models did not predict well the heat transfer coefficient in small diameter tubes, Qu and Mudawar (2003), Owhaib and Palm (2003) and Huo et al. (2007).

More complex behaviour and differences dependent on the fluid tested were reported by other researchers. For example, Di'az and Schmidt (2007) investigated transient boiling heat transfer in $0.3 \times 12.7 \mathrm{~mm}$ microchannels using infrared thermography to measure the wall temperature. For water, the heat transfer coefficient decreased with quality near the zero quality region followed by a uniform heat transfer coefficient. However, for ethanol at high quality, an increase in heat transfer coefficient with quality was found to be independent of applied heat flux. A similar behaviour, i.e. an increase in the heat transfer coefficient with quality, was observed by $\mathrm{Xu}$ et al. (2005) and Lin et al. (2001). Lie et al. (2006) investigated experimentally evaporation heat transfer of R134a and R407c flow in horizontal small tubes of 0.83 and $2.0 \mathrm{~mm}$ internal diameter. The heat transfer coefficient was observed to increase with quality almost linearly, except at lower mass flux and heat flux. It also increased with heat flux, mass flux and saturation pressure. The fluid was preheated to an inlet quality that varied from 0.2 to 0.8 . Saitoh et al. (2005) studied the effect of tube diameter on boiling heat transfer of R134a in horizontal tubes with inner diameter of 0.51 , 1.12 and $3.1 \mathrm{~mm}$. The heated lengths were $3.24,0.935$, and 0.550 $\mathrm{m}$ respectively. The heat flux ranged from 5 to $39 \mathrm{~kW} / \mathrm{m}^{2}$, mass flux from 150 to $450 \mathrm{~kg} / \mathrm{m}^{2} \mathrm{~s}$, saturation pressure from 3.5 to 4.7 bar and inlet vapour quality 0 to 0.2 . For the $3.1 \mathrm{~mm}$ tube, when the quality was less than 0.6 , the heat transfer coefficient was strongly affected by heat flux and was not a function of mass flux and quality. For quality greater than 0.5 , heat transfer coefficient increased with mass flux and quality, but was not affected by heat flux. This quality limit shifted to 0.4 , for the $1.12 \mathrm{~mm}$ tube. The $0.51 \mathrm{~mm}$ results did not exhibit the same heat transfer characteristic as the rest of the tubes. When the quality was less than 0.5 , the heat transfer coefficient seemed to increase with quality and heat flux and slightly with mass flux. In this region, the heat transfer coefficient was slightly higher than the 1.12 and $3.1 \mathrm{~mm}$ tubes. There was also an early dryout compared with the other tubes, and the region of decreasing heat transfer coefficient with quality is not such a sharp drop as the rest. They observed flow instabilities in the two larger tubes (3.1 and $1.12 \mathrm{~mm})$, but not with in the $0.51 \mathrm{~mm}$ tube. Agostini and Thome (2005) categorized the trends in the local heat transfer coefficient versus vapour quality and its relation to heat and mass flux after reviewing thirteen different studies. They noted that in most of the cases reviewed that at low quality $(<0.5)$ the heat transfer coefficient increases with heat flux and decreases or is relatively constant with vapour quality and at high vapour quality it decreases sharply with vapour quality and is independent of heat flux or mass flux.

\section{Initiation of Boiling}

Flow boiling in very small diameter tubes is usually associated with high initial liquid superheat required to initiate boiling. Yen et al. (2003) conducted flow boiling experiments in $0.19,0.3$ and $0.51 \mathrm{~mm}$ inside diameter tubes using R123 and FC-72. They observed a high liquid superheat that reached up to $70 \mathrm{~K}$ in their experiments. In the low quality region, the heat transfer coefficient was observed to decrease with quality up to approximately $\mathrm{x}=0.25$ and then became almost constant with further increase in quality. Hapke et al. (2000) investigated boiling in a $1.5 \mathrm{~mm}$ internal diameter tube and reported that the onset of boiling occurred at higher liquid superheat than required for conventional tubes. Peng and Wang (1993) and Peng et al. (1998), based on their observations of boiling in microchannels of hydraulic diameter $200-600 \mu \mathrm{m}$, argued that nucleation can hardly be seen in microchannels. They proposed a hypothesis of 'evaporating space' to explain the phenomenon. They also suggested a theoretical model to predict the superheat temperature. The unusually high superheat in micro tubes was also reported to be related to the reduction of active nucleation sites and vapour nucleation inside very small channels, Zhang et al. (2001) and Brereton (1998).

\section{Temperature and Pressure Fluctuations}

Microchannel flow boiling studies have demonstrated a decrease in heat transfer coefficient with increasing quality, often accompanied by fluctuating wall temperatures, e.g. Lin et al. (2001), Yan and Lin (1998), Wen et al. (2002), Huo et al. (2007). These have been attributed to transient dryout, particularly at low mass flux, and relatively high heat flux. Kenning et al. (2006) suggested that there are two different mechanisms of dryout around individual bubbles in microchannels. These are dryout as a result of depletion of the film thickness below a certain minimum by complete evaporation of the liquid film beneath the confined bubble and dryout due to surface tension driven 'capillary roll-up' on partially-wetted surfaces with finite contact angles. Experimental studies also indicated fluctuations in pressure and wall temperature. Yan and Kenning (1998) investigated water boiling at atmospheric pressure in a $2 \times 1 \mathrm{~mm}$ channel. They showed that the pressure fluctuations were caused by the acceleration of liquid slugs by expanding confined bubbles, confirming a model of Kew and Cornwell (1996), and that the corresponding fluctuations in saturation temperature were of similar magnitude to the mean superheat causing evaporation, so they could not be neglected. 


\section{Effect of Decreasing Diameter}

There are a limited number of experiments that have tested a wide range of tube diameter to investigate the heat transfer trend with channel size. Studies that have considered the effect of diameter are reviewed briefly below. Yan and Lin (1998) conducted experiments with R134a using a single tube of internal diameter $2.0 \mathrm{~mm}$ and heated length $100 \mathrm{~mm}$. They claimed that the evaporation heat transfer coefficient increased by $30 \%$ to $80 \%$ compared with conventional diameter tubes. Oh et al. (1998) experimentally investigated the evaporation heat transfer for three different copper tubes of diameter $0.75,1.0$ and $2.0 \mathrm{~mm}$ using R134a. For vapour quality less than 0.6, they found the heat transfer coefficient for the $1.0 \mathrm{~mm}$ tube to be higher than that of the $2.0 \mathrm{~mm}$ tube by approximately $45 \%$. However, decreasing the tube diameter shifted to a lower quality the point at which the heat transfer coefficient started to decrease axially, presumably due to dryout. Owhaib et al. (2004) studied experimentally evaporative heat transfer using R134a in vertical circular tubes of internal diameter $1.7,1.22$, and $0.83 \mathrm{~mm}$, and a uniform heated length of $220 \mathrm{~mm}$. Other parameters range as: mass flux $50-400 \mathrm{~kg} / \mathrm{m}^{2} \mathrm{~s}$, heat flux $3-34 \mathrm{~kW} / \mathrm{m}^{2}$ and pressure 6.5 -8.6 bar. They concluded that the heat transfer coefficient increased with decreasing tube diameter.

In general, experimental results indicate an increase in the heat transfer coefficient as the diameter decreases. However, some contradictory results are also available. For example, Kuwahara (2000) experimentally studied the flow boiling heat transfer characteristic and flow pattern inside 0.84 and $2.0 \mathrm{~mm}$ diameter tubes using R134a and found no difference in the heat transfer characteristic between the two tubes. Baird et al. (2000) conducted boiling experiments on tubes of 0.92 and $1.95 \mathrm{~mm}$ diameter and found no significant effect of diameter on the heat transfer coefficient. Khodabandeh (2003) studied boiling in a two phase thermosyphon loop with iso-butene as a working fluid with tubes ranging from 1.1 to $6 \mathrm{~mm}$ in diameter. He also concluded that the effect of diameter was small and not clear. In the work of Saitoh et al. described above, there was no obvious effect of diameter on heat transfer coefficient or it was not straightforward to deduce the influence.

A theoretical three-zone model for predicting the local dynamic and local time-averaged heat transfer coefficient was presented by Thome et al. (2004) and Dupont et al. (2004). The model is based on convective heat transfer in the confined bubble regime without a contribution from nucleate boiling. The model predictions indicate that the heat transfer coefficient increases with diameter for quality greater than 0.18 , while it decreases with diameter for quality less than 0.04. Dupont and Thome (2005) compared the model results with the experiments of Owhaib and Palm (2004). The model did not predict the trend of increasing heat transfer coefficient with decreasing diameter. Instead an opposite prediction was observed in the quality range covered. Dupont and Thome (2005) noted the lack of adequate experimental data covering a wide range of tube diameter for boiling heat transfer. The model predictions were also compared with experimental data for R134a and tubes of 2.01 and $4.26 \mathrm{~mm}$ in diameter by Shiferaw et al. (2007); they reported that the model predicts that the diameter has an opposite effect on the heat transfer coefficient compared to the measured data.
The above brief overview indicates that a lot of work is still necessary to elucidate the effect of diameter on the rate and mechanism of heat transfer, including the possible diameter thresholds for distinguishing macro, small and microscale characteristics. Although more than two tubes were used in some of the past studies, it was not possible to identify the influence of diameter because different conditions were used for different diameter tubes. Therefore the experimental facility described in the next section was used to determine the heat transfer coefficients for R134a in five different diameter tubes for similar wide ranges of heat and mass fluxes and pressure, combined with flow visualization at the exit to the test section.

\section{EXPERIMENTAL FACILTY AND PROCEDURE}

The experimental facility consists of three main systems, which are the R134a main circuit, data acquisition and control, and the R22 cooling system. The main facility, which is shown in Figure 3, was designed to allow testing of different fluids and a wide range of flow conditions. Details of the experimental system were described in Huo et al. (2007). The test sections were made of stainless steel cold drawn tubes. The dimensions of the five test tubes are given in Table 1. They were heated by the direct passage of alternating electric current. The outer wall temperatures for the $4.26 \mathrm{~mm}$ to 1.1 $\mathrm{mm}$ tubes were measured using fifteen K-type thermocouples that were soldered to the outside of the tube at a uniform spacing. The first and last thermocouple readings were not used in the analysis so as to avoid errors due to thermal conduction to the electrodes. Ten thermocouples were soldered on the $0.52 \mathrm{~mm}$ tube - the two at each end were located sufficiently far from the electrodes to be used in the data analysis. The pressures and temperatures at the inlet and outlet were measured using pressure transducers and T-type thermocouples. A differential pressure transducer was installed across the test section to provide the pressure drop measurement. At the exit to the heating section, a borosilicate glass tube for flow pattern observation was located. A digital high-speed camera (Phantom V4 B/W, 512 x 512 pixels resolution, 1000 pictures/sec with full resolution and maximum 32000 pictures/sec with reduced resolution, $10 \mathrm{~ms}$ exposure time) was used to observe the flow patterns.

A series of flow boiling tests were then performed at different mass flux and heat flux. During these tests, the inlet temperature was controlled at a subcooling of $1-5 \mathrm{~K}$ by adjusting the capacity of the chiller and heating power to the preheater. The flow rate was set to the required value and the heat flux was increased in small steps until the exit quality reached about $90 \%$. The data were recorded after the system was steady at each heat flux, which normally took about 15 minutes but sometimes longer. Each recording was the average of 20 measurements. The next test was then performed at a different flow rate. All the instruments used were carefully calibrated. Tables 1 and 2 summarize the range and uncertainties of the important parameters. 


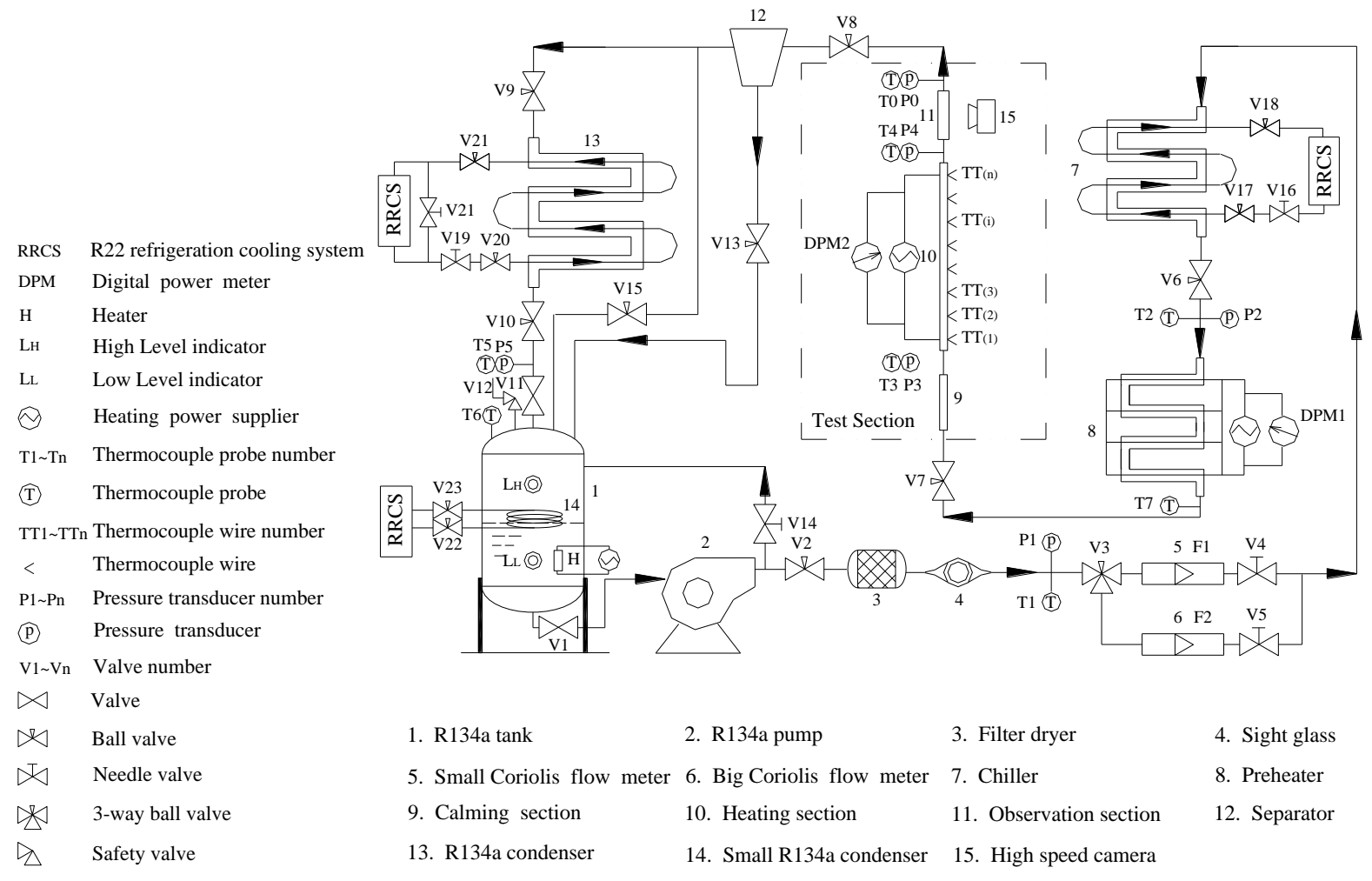

Figure 3. Schematic diagram of the experimental system.

\section{DATA REDUCTION}

The local heat transfer coefficient $\alpha(z)$ at each thermocouple position was calculated using local values of the inside wall temperature and the saturation temperature and is given by:

$$
\alpha(z)=\frac{q}{\boldsymbol{\sigma}_{w i z}-\boldsymbol{\Gamma}_{s_{z}}}
$$

Table 1 Range of experiment parameters

\begin{tabular}{ll}
\hline Parameters & Range \\
\hline Diameter & $4.26,2.88,2.01,1.10$ and $0.52 \mathrm{~mm}$ \\
Wall thickness & $0.245,0.15,0.19,0.247$ and 0.15 \\
Heated length & $500,300,211,150$ and $100 \mathrm{~mm}$ \\
Roughness & $1.75,1.54,1.82,1.28$ and $1.15 \mu \mathrm{m}$ \\
Mass flux & $100-700 \mathrm{~kg} / \mathrm{m} 2 \mathrm{~s}$ \\
Heat flux & $1.6-150 \mathrm{~kW} / \mathrm{m} 2$ \\
Vapour quality & $0-0.9$ \\
Pressure & $6,8,10,12$, and 14 bar \\
\hline
\end{tabular}

Table 2 Measurement uncertainty

\begin{tabular}{ll}
\hline Parameter & Uncertainty \\
\hline Temperature & $0.16 \mathrm{~K}$ \\
Pressure & $0.15-0.27 \%$ \\
Differential Pressure Drop & $0.27-0.30 \%$ \\
Mass flux & $0.44 \%$ \\
Heat flux & $0.5-1.5 \%$ \\
Heat transfer coefficient & $6-12.5 \%$ \\
\hline
\end{tabular}

where $q$ is the inner wall heat flux to the fluid determined from the electric power supply to the test section and the heat loss. $T_{w i}$ is the local inner wall temperature, which can be determined using the internal heat generation and radial heat conduction across the tube wall as given by:

$$
T_{w i}=T_{w o}-\frac{q \cdot d_{i}}{4 k}\left[\frac{\mathbb{Q}_{i} / d_{o} \boldsymbol{j}-2 \ln \mathbf{Q}_{i} / d_{o} \mathcal{j} 1}{1-\mathbf{Q}_{i} / d_{o} \boldsymbol{j}}\right]
$$

$T_{s}$ is the local saturation temperature, deduced from the local fluid pressure assuming a linear pressure drop across the test section. The local specific enthalpy, $h_{i}$, at each thermocouple position was determined from the energy balance in each heated section considering the losses:

$$
h_{i}=h_{i-1}+\frac{L_{i}}{\dot{m} L}(Q-\Delta Q)
$$

where the heat transfer $(\mathrm{Q})$ is the total electric heat input, which is equal to the product of the voltage and the current applied directly to the test section. $(\Delta \mathrm{Q})$ is the heat loss determined using the loss coefficient obtained from singlephase test before each series of boiling tests, see also Huo (2007). Therefore the local vapour quality can be calculated from the local specific enthalpy at each thermocouple position and is given as:

$$
x_{i}=\frac{h_{i}-h_{l}}{h_{v}-h_{l}}
$$

where, $h_{l}$ and $h_{v}$ are the specific enthalpy of saturated liquid and vapour, respectively. 


\section{SINGLE PHASE RESULTS}

Single phase pressure drop and heat transfer tests were conducted for the largest diameter tube before commencing the boiling experiments. These were performed to determine the heat loss coefficient and for the purpose of validating the experimental technique, i.e. data acquisition, calibration procedure and overall instrumentation by comparing with the well known single-phase pressure drop and heat transfer correlations. The results of one of the comparisons are presented in Figure 4. The single-phase friction factor results, Figure 4 (a) agree well with the Blasius (1913) correlation, i.e. within the uncertainty of the experiment. Also, the single phase $\mathrm{Nu}$ number results, Figure 4 (b), agree very well with DittusBoelter (1930) and Petukhov (1970) correlation; again below the uncertainty limit. The above results verified the overall accuracy of the experimental system. Experimental accuracy becomes an increasing difficult challenge as the size of the passages decreases and either laminar or turbulent flow may exist, depending on the mass flow rate. Therefore, additional single-phase experiments were performed with the $0.52 \mathrm{~mm}$ tube to assess the ability of the test rig to produce accurate results at this small diameter. The comparisons of the experimental results with past results and known correlations were presented in Shiferaw et al. (2008). The results agreed fairly well with the modified Gnielinski (1997) and Adams et al. (1998) for the turbulent regime and Choi et al. (1991) in the laminar regime. The reproducibility of the boiling tests was also verified. The different test results were mostly within the range of uncertainty of the data, see Shiferaw et al. (2008). The above set of experiments confirmed the adequate accuracy and validity of the present results.

\section{EXPERIMENTAL RESULTS AND DISCUSSION}

\section{Flow Pattern Results}

Figure 5 (a) and (b) presents the flow patterns observed during the boiling test at a mass flux of $400 \mathrm{~kg} / \mathrm{m}^{2} \mathrm{~s}$ and pressure 8 bar for the $0.52 \mathrm{~mm}$ tube and should be compared with the results of Chen et al. (2006), obtained with the same test facility and procedure depicted in Figure 1. These flow patterns were taken simultaneously with the heat transfer tests presented hereinafter at each value of heat flux. They represent the more frequently observed flow pattern for the particular heat flux. However, more than one type of flow pattern occurred intermittently in some cases. Image 1 shows bubbly flow. Confined bubble flow (images 2 and 3) was observed at low heat flux or exit quality. As the heat flux increased, the bubbles grew in length and became elongated. Further increase in heat flux resulted in the liquid slug between the bubbles being "pushed" on to the upstream bubble creating coalescence of the bubbles and a wavy film. A similar phenomenon was observed by Revellin et al. (2006). Figure 5 (b) shows a sequence of how three relatively short bubbles coalesce in the adiabatic viewing section to form an elongated bubble, leaving the liquid film interface wavy. Note that these observations

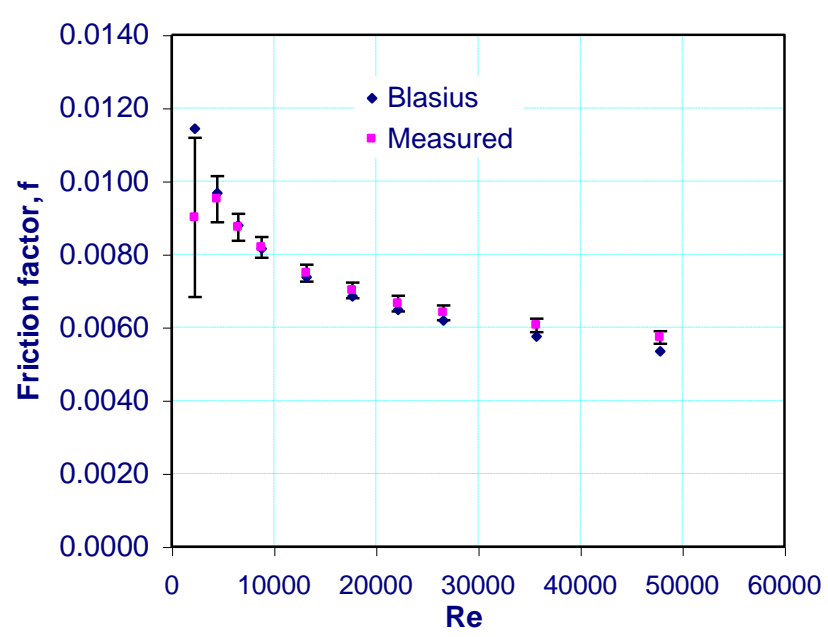

(a)

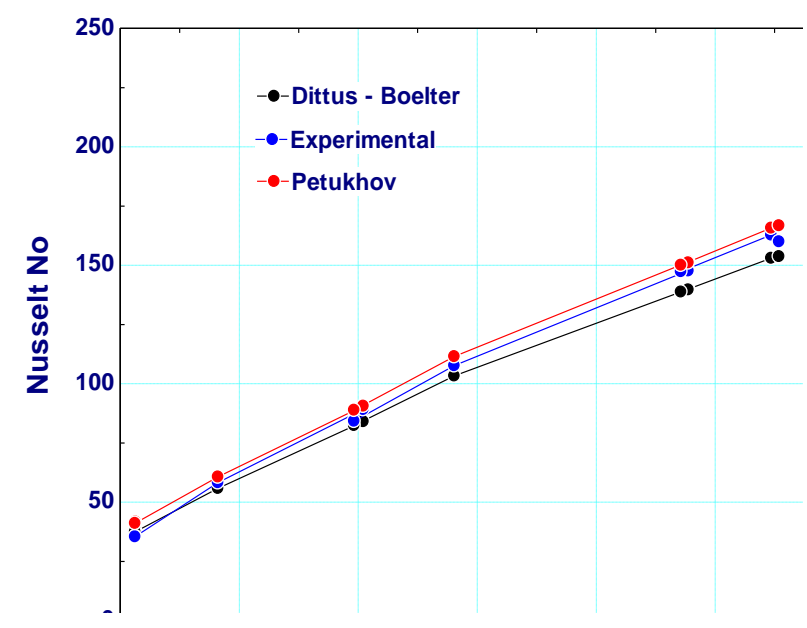

(b)

Figure 4. Single phase results for $\mathrm{d}=4.26 \mathrm{~mm}$ at $7.5 \mathrm{bar}$ (a) friction factor vs. Re, (b) Nusselt number vs. Re.

were carried out at the exit of the test section and coalescence may be different in the heated section. As shown again in Figure 5 (a), when increasing the heat flux even further, liquid ring flow is obtained for a relatively wide range of quality (images 4-6). In this case, the film interface is wavy and highly non-uniform. This could lead to a transition to annular flow (image 7), since further increase in heat flux reduces the wave irregularity and distributes the waves almost uniformly - annular flow (images 8-10). At high heat flux, the annular flow patterns have small-scale roughness of very short amplitude and wavelength.

Overall, the flow patterns observed in the smaller tube of internal diameter $0.52 \mathrm{~mm}$ were different from those observed in the larger tubes by Chen et al. (2006). These include the absence of dispersed flow, while ring flow becomes more visible. In this tube, liquid lump flow (see Serizawa et al. 2002) was not observed. 

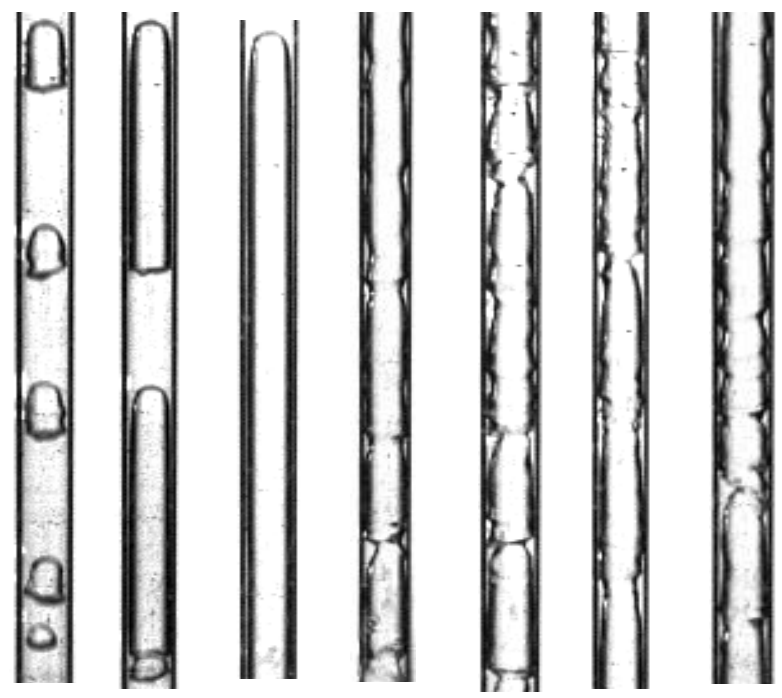

1
3
5

6
7

(a)

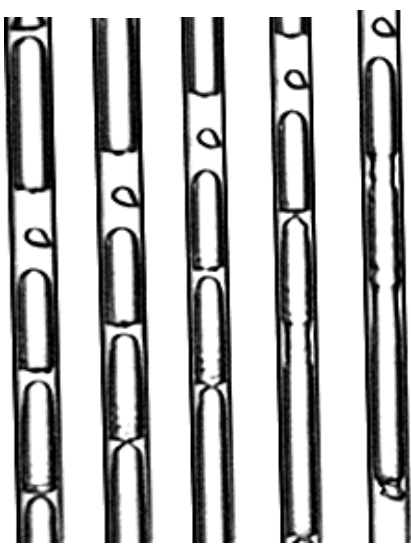

Figure 5.

(a) Flow pattern in of $0.52 \mathrm{~mm}$ tube at $400 \mathrm{~kg} / \mathrm{m}^{2} \mathrm{~s}$ and 8 bar;

(b) sequence of flow patterns showing coalescence.

\section{Heat Transfer Results}

Typical experimental data for the five tubes are plotted as graphs of heat transfer coefficient vs. quality, the presentation conventionally used for large tubes. This implies that heat transfer depends only on local flow conditions and not on how the flow is developed, so that the convective component depends on the local flow pattern. The relationship between flow pattern observations in an adiabatic section at the exit from the tube and the flow pattern within the heated section at the same quality may require examination for the particular conditions in small tubes, in which the growth of an individual bubble may influence a considerable length of the tube.

Data at a pressure of 8 bar and a mass flux of $400 \mathrm{~kg} / \mathrm{m}^{2} \mathrm{~s}$ in the tubes with diameters $4.26-0.52 \mathrm{~mm}$ are plotted in Figure 6 (a)-(e). As seen in, for example figure 6 (a) for the $4.26 \mathrm{~mm}$ tube, at a quality $x<0.5$ approximately and moderate heat flux, the heat transfer coefficient is constant within $\pm 10 \%$ at a value that increases with heat flux and pressure, but which is independent of quality. Huo et al. (2007) and Shiferaw et al. (2007) reported similar trends at 8 bar and a mass flux of 300 $\mathrm{kg} / \mathrm{m}^{2} \mathrm{~s}$ in the 4.26 and $2.01 \mathrm{~mm}$ tubes, Within this range, the local variations appear to follow a pattern associated with the

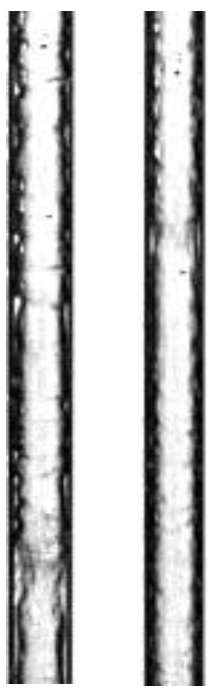

8

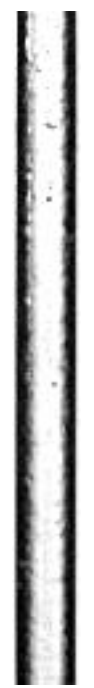

9

10

\begin{tabular}{llll}
\hline No & $\begin{array}{l}\mathrm{q} \\
\left(\mathrm{kW} / \mathrm{m}^{2}\right)\end{array}$ & $\begin{array}{l}\mathrm{U}_{\mathrm{gs}} \\
(\mathrm{m} / \mathrm{s})\end{array}$ & $\begin{array}{l}\mathrm{U}_{\mathrm{ls}} \\
(\mathrm{m} / \mathrm{s})\end{array}$ \\
\hline 1 & 9.5 & 0.92 & 0.31 \\
2 & 12.8 & 1.33 & 0.29 \\
3 & 14.1 & 1.5 & 0.29 \\
4 & 17.9 & 1.97 & 0.27 \\
5 & 25.3 & 3.11 & 0.24 \\
6 & 31.0 & 3.97 & 0.21 \\
7 & 43.5 & 4.93 & 0.18 \\
8 & 49.2 & 6.11 & 0.14 \\
9 & 55.5 & 7.06 & 0.11 \\
10 & 61.4 & 8.05 & 0.073 \\
\hline
\end{tabular}

axial positions of the measuring stations. As the variations do not appear in single-phase flow experiments, they are not associated with individual thermocouples or wall roughness that would affect the liquid flow. They may indicate variations in wall characteristics that affect bubble nucleation or the stability of thin liquid films round confined bubbles. At higher quality and/or heat flux, these patterns change to a general tendency for the heat transfer coefficient to decrease with increasing quality and to converge on a single line that is independent of heat flux. This trend cannot be fully confirmed in these experiments with a fixed heated length for a given diameter of tube, since high quality cannot be achieved at low heat flux. However, one can also observe that the quality at which the heat transfer coefficient becomes independent of heat flux and decreases with quality moves to lower values of quality as the diameter is reduced (e.g. at approximately $\mathrm{x}=0.5$ for $\mathrm{d}=4.26 \mathrm{~mm}$ and $\mathrm{x}=0.3$ for $\mathrm{d}=2.01 \mathrm{~mm})$.

At very high heat flux, the heat transfer coefficient can decrease with heat flux. The effect is particularly marked in the $2.01 \mathrm{~mm}$ tube, Figure $6(\mathrm{c})$ for $\mathrm{q}=95-134 \mathrm{~kW} / \mathrm{m}^{2}$. The heat flux and quality at which this occurs both decrease with decreasing tube diameter. Shiferaw et al. (2007) and Huo et al. (2007) reported that the tube wall temperature was highly unstable in this particular region, which could indicate the occurrence of partial (intermittent) dryout with a long timescale. Lin et al. (2001) and Sumith et al. (2003) observed wall temperature fluctuations that increased as the heat flux increased. This was assumed to be related to time varying local heat transfer coefficient and local pressure, Lin et al. (2001), Wen et al. (2002).

The behaviour in the $0.52 \mathrm{~mm}$ tube at the same pressure and mass flux is significantly different, Figure 6(e). For this tube, the liquid-only Reynolds number is 1100 , which should correspond to laminar flow at the inlet, unlike the liquid only $R e$ numbers in the 4.26, 2.88, 2.01 and $1.1 \mathrm{~mm}$ tubes which were $9500,6400,4500$ and 2500 respectively. There is a different dependence of the heat transfer coefficient on heat flux and vapour quality below and above a heat flux of 17.9 $\mathrm{kW} / \mathrm{m}^{2}$. This heat flux threshold coincides with the appearance of liquid rings that no longer bridge the tube, see image 4 in Figure 5(a), and the disappearance of the small 
superheat that is recorded by the thermocouple in the exit flow. At the low heat fluxes, the heat transfer coefficient does not depend on heat flux and decreases slightly with quality.

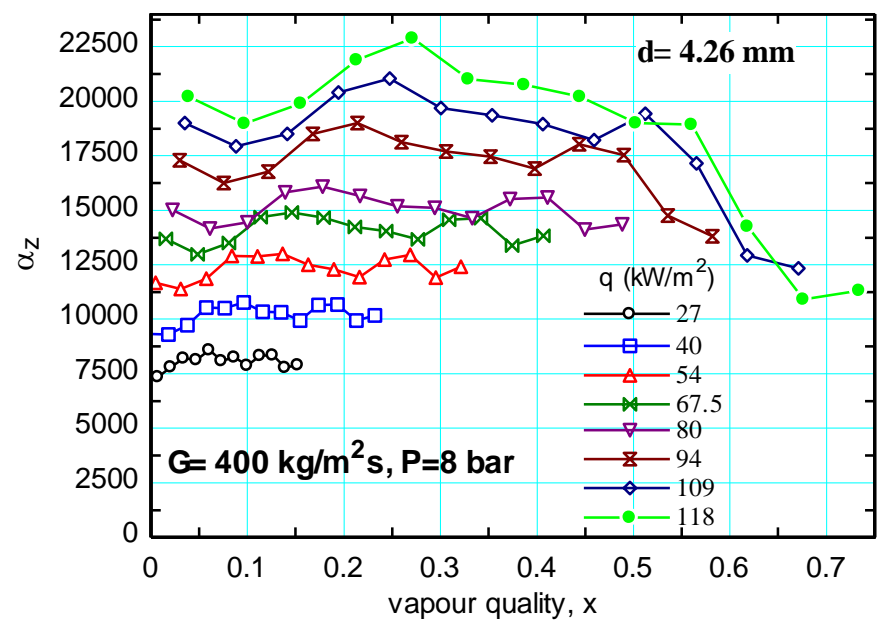

(a)

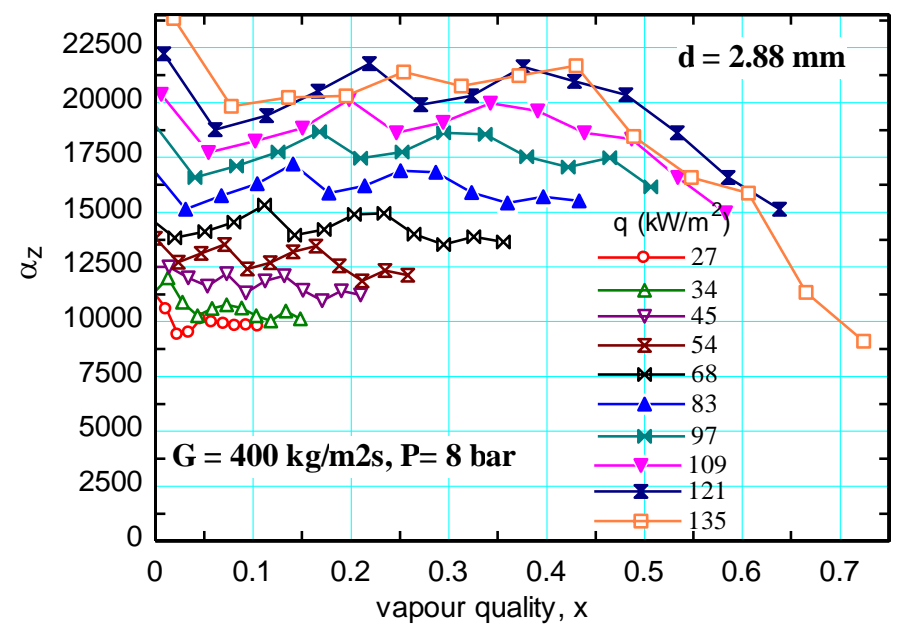

(b)

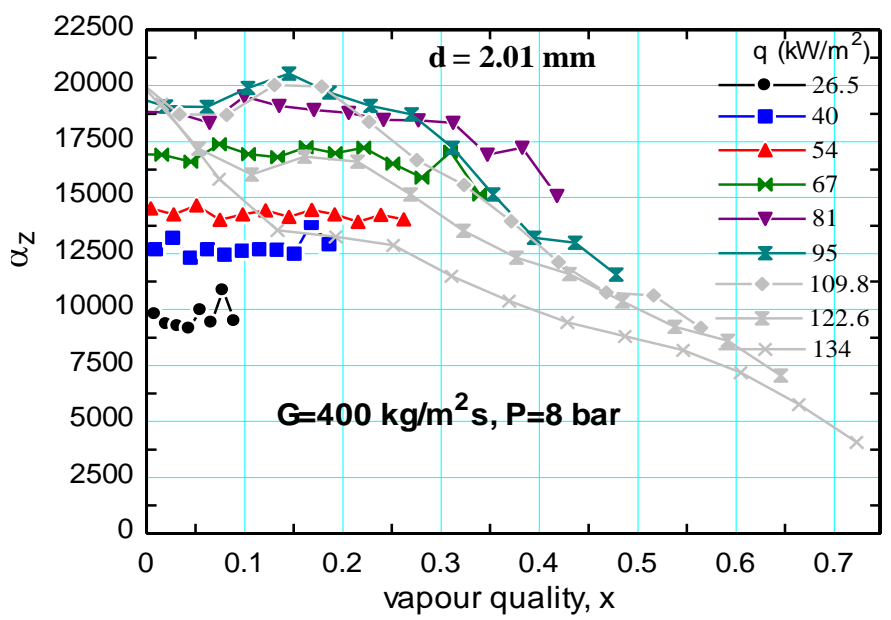

(c)

Figure 6. Local heat transfer coefficient as a function of vapour quality at mass flux $400 \mathrm{~kg} / \mathrm{m}^{2} \mathrm{~s}$ and pressure 8 bar: (a) 4.26 mm; (b) $2.88 \mathrm{~mm}$; (c) $2.01 \mathrm{~mm}$; (d) $1.10 \mathrm{~mm}$; (e) $0.52 \mathrm{~mm}$.

However, it must be noted that the data here are limited to $\mathrm{x}<$ 0.15 . At these low heat flux values a longer tube would be required to reach high exit quality. There is an abrupt increase in the heat transfer coefficient and a change in its trend with quality and heat flux at heat fluxes of $17.9 \mathrm{~kW} / \mathrm{m}^{2}$ and above.

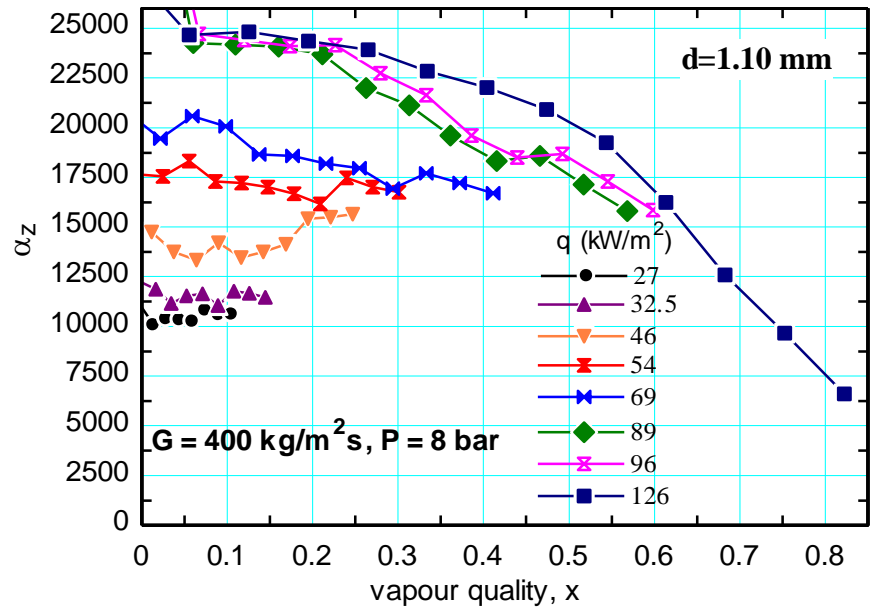

(d)

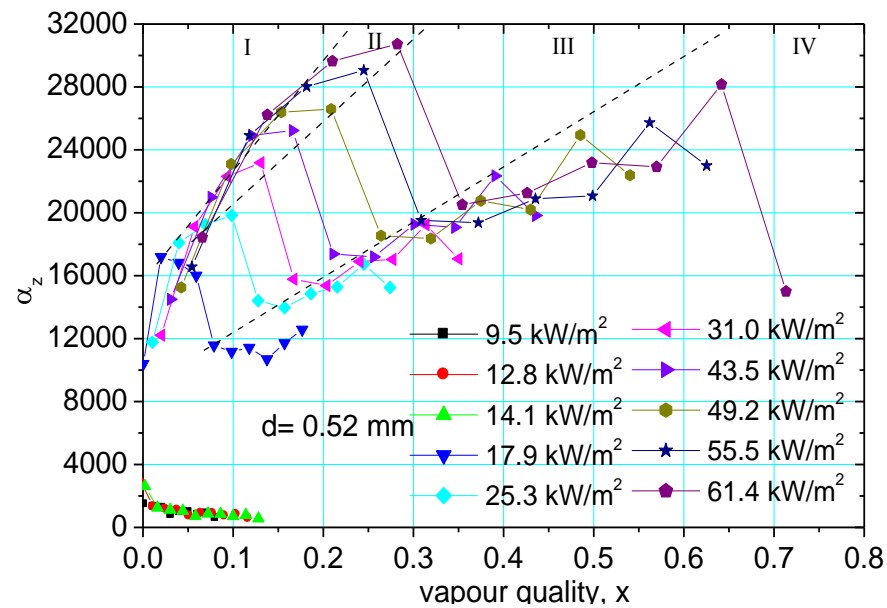

(e)

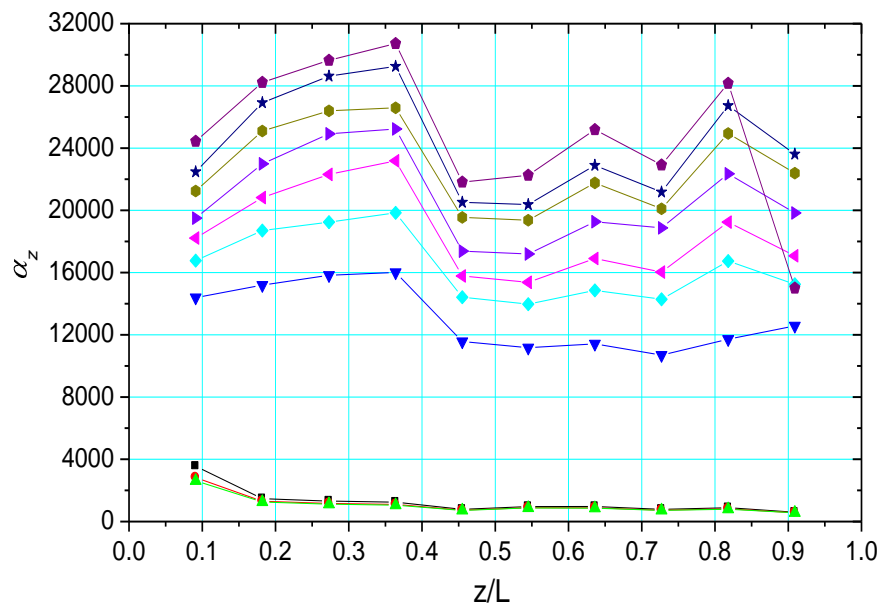

Figure 7. Heat transfer coefficient vs. axial distance at mass flux $400 \mathrm{~kg} / \mathrm{m}^{2} \mathrm{~s}$ and pressure 8 bar for $0.52 \mathrm{~mm}$ tube. Heat flux values as in Figure 6 (e).

At these heat fluxes, the heat transfer coefficient initially increases rapidly with quality, Figure 6(e). The data points for all heat fluxes converge on approximately the same line as far as the 3rd thermocouple in zone I. The initial variations may be influenced by the small differences in the low inlet subcooling. In zone II, between the $3 \mathrm{rd}$ and 4 th thermocouples, the heat transfer coefficient levels off at a maximum value that depends on the heat flux. This is followed by a large reduction in heat transfer coefficient in zone III between the 4th and 5th thermocouples. After that, 
the data fall on another line of increasing heat transfer coefficient that, within experimental error, is almost independent of heat flux in zone IV. At the highest heat flux only, there is a large fall in the heat transfer coefficient at the last measuring point at a quality $\mathrm{x}=0.71$. This is not reproduced in other runs at nearly the same conditions, so it may indicate that the system is on the threshold of the transient dryout that is thought to cause the reduction in heat transfer coefficient with increasing quality in the larger tubes. Because of this behaviour at high exit quality, the maximum heat flux in the tests on the $0.52 \mathrm{~mm}$ tube was approximately half that used in the tests on our larger tubes at the same mass flux. As in the larger tubes, the pattern of variation of the heat transfer coefficient appears to be related to the axial positions of the measuring stations, Figure 7.

Figure 8 is a plot similar to Figure $6(\mathrm{e})$ for the same 0.52 $\mathrm{mm}$ tube at a lower mass flux of $300 \mathrm{~kg} / \mathrm{m}^{2} \mathrm{~s}$ (liquid-only $\mathrm{Re}$ number 720) and a lower pressure of 6 bar, reported in Shiferaw et al. (2008). It confirms that the heat transfer characteristics of this tube are indeed different from the larger tubes. There are again two groups of data, this time separated by a threshold heat flux of $12.5-14.8 \mathrm{~kW} / \mathrm{m}^{2}$, which also appears to coincide with the change of slug or confined flow to ring flow at the exit from the heated section. At the low heat fluxes, the heat transfer coefficient is approximately independent of heat flux although, in contrast to Figure 6(e), it initially falls significantly with quality and then exhibits a weak increase. At values higher than $14.8 \mathrm{~kW} / \mathrm{m}^{2}$, the $\alpha$ vs. $\mathrm{x}$ plot follows the same general pattern of axial development through zones I - IV seen in Figure 6(e), except that the values of axially increasing heat transfer coefficient in zone I depend on heat flux and the influence of heat flux extends into zone IV, where the heat transfer coefficient again increases axially. The test section is not long enough at low heat fluxes to show for certain whether the data converge on a line independent of heat flux at high quality. For heat fluxes above the threshold value, the pattern of variations in $\alpha$ appears to depend on the fraction of heated length $\mathrm{z} / \mathrm{L}$, Figure 9, but the pattern is not exactly the same as in Figure 7. The maximum heat transfer coefficient now occurs at thermocouple 3 instead of 4 . The subsequent reduction in zone III is less abrupt, still continuing to thermocouple 5. There are also differences in the detail of the pattern in zone IV. If the pattern depends on the effect of local roughness on local nucleation of bubbles, the effect must be moderated by the changes in flow conditions and system pressure.

Yet another way of plotting the same data in Figures 8, 9 is as boiling curves at measuring points $3-8$, Figure 10, Shiferaw et al. (2008). The plots look like pool boiling curves for increasing heat flux in a system with nucleation hysteresis at $12.5 \mathrm{~kW} / \mathrm{m}^{2}$. If the nucleation characteristics vary axially, it is unlikely that the same threshold would apply at all stations. It seems more likely that nucleation occurs at upstream sites and that downstream positions are influenced by the growth of individual confined bubbles that may cover a long axial length. It is impossible to observe local nucleation in a metal tube and the observations of flow patterns are restricted to the tube exit. Confined bubble flow with smooth liquid films round long bubbles, as assumed in the Thome et al. (2004) convective model, is observed with low heat transfer coefficients just below the threshold heat flux, as in Figure 5(a) image 3 at 400 $\mathrm{kg} / \mathrm{m}^{2} \mathrm{~s}$, and ring flow just above the threshold. The large increase in heat transfer coefficient above the threshold occurs throughout the length of the tube and particularly near the inlet in zones I and II, so it cannot be caused by a gradual progression from the exit towards the inlet of a flow regime transition at a particular quality. Further investigation is required of whether nucleation is triggered at a single site, which could exert downstream influence through the bubble frequency that is an important parameter in the Thome et al. model for convective evaporation, or at more widely distributed sites. The availability of sites may become subject

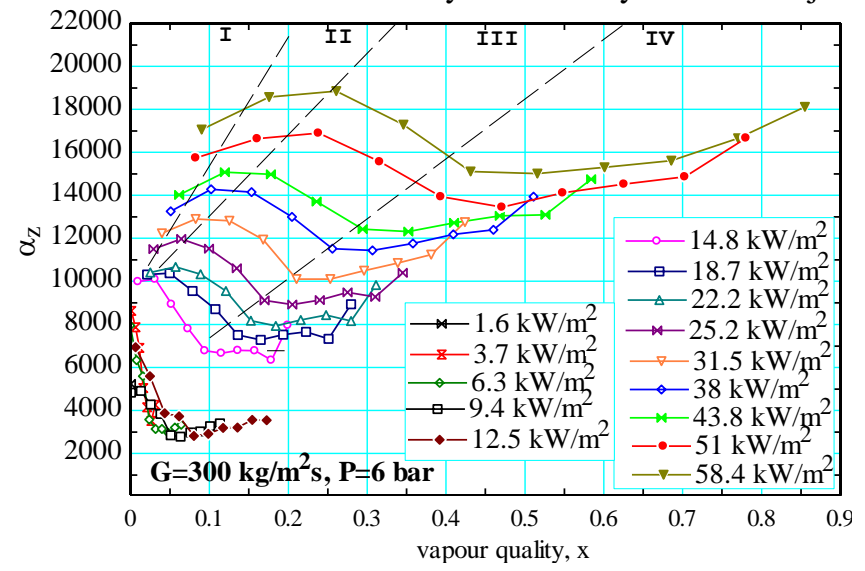

Figure 8. Heat transfer coefficient vs. quality at mass flux $300 \mathrm{~kg} / \mathrm{m}^{2} \mathrm{~s}$, pressure 6 bar in the $0.52 \mathrm{~mm}$ tube.

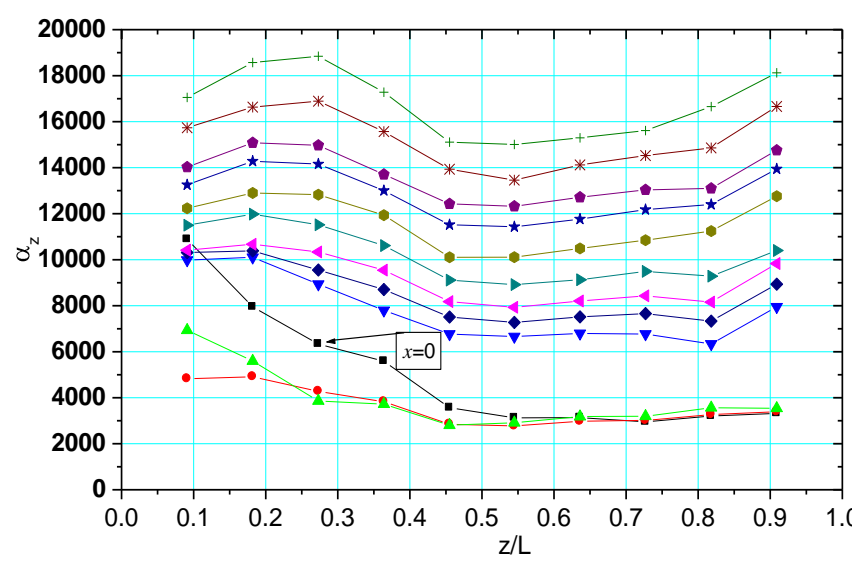

Figure 9. Heat transfer coefficient vs. axial distance at mass flux $300 \mathrm{~kg} / \mathrm{m}^{2} \mathrm{~s}$, pressure 6 bar in $0.52 \mathrm{~mm}$ tube. (The marker $\mathrm{x}=0$ indicates the position where saturation is achieved for $\mathrm{q}=1.6 \mathrm{~kW} / \mathrm{m}^{2}$. For the rest, this happens at/before the first thermocouple position.)

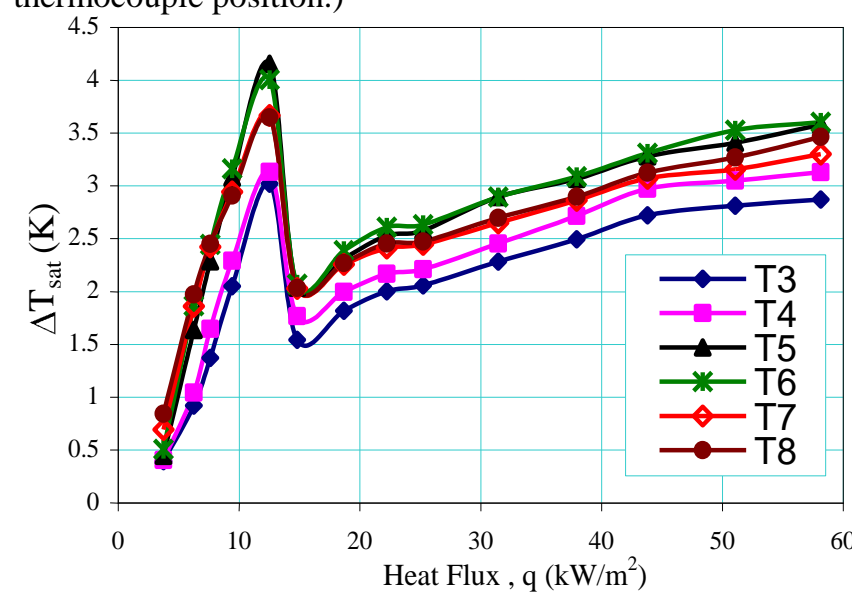


Figure 10. Wall superheat vs. heat flux at mass flux 300 $\mathrm{kg} / \mathrm{m}^{2} \mathrm{~s}$, pressure 6 bar at each measuring station for the 0.52 qualities. Convective models for high quality will have to account for the disturbances to the liquid film.

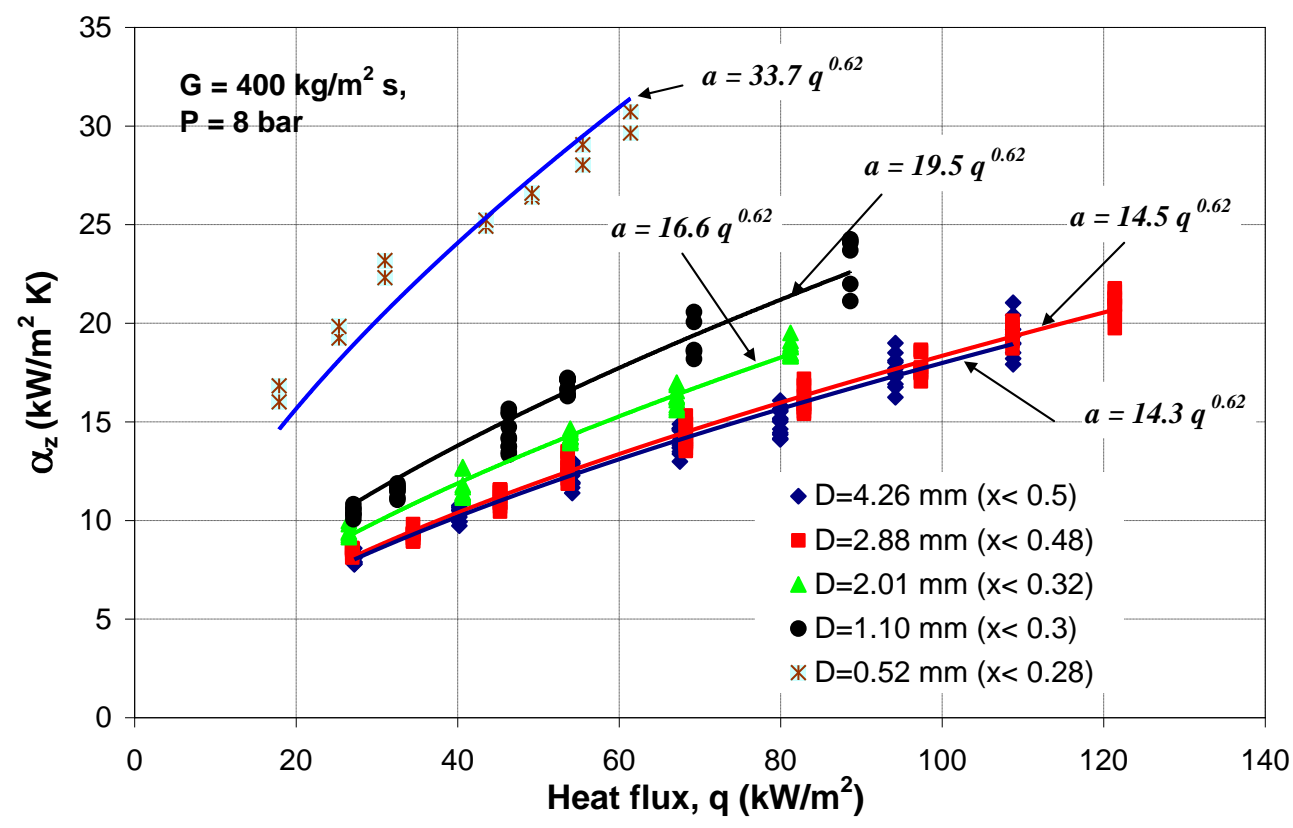

Figure 11. Effect of diameter on heat transfer coefficient at $400 \mathrm{~kg} / \mathrm{m}^{2}, 8$ bar, low $\mathrm{x}$.

mm tube.

to large statistical variability as the surface area decreases with decreasing tube diameter, Zhang et al (2001), Brereton (1998).

A further special feature of the $0.52 \mathrm{~mm}$ tube is the decrease in the heat transfer coefficient in zone III, commencing at a quality that increases with increasing heat flux, followed by constant or increasing heat transfer coefficient in zone IV, with a fall very close to the tube exit in some runs. It is therefore likely to have a different mechanism from the axial decrease in heat transfer coefficient observed in the larger tubes of this study, which commences at a quality that decreases with increasing heat flux and is then maintained to the end of the tube. Because of its association with a particular axial length of the tube, the heat transfer in zone III of the $0.52 \mathrm{~mm}$ tube may depend on interactions between nucleation sites and the changing flow regime. From the observations of the exit flow, Figure 5(a), the flow in zone IV is annular, with intensive disturbances to the liquid film that decrease in scale with increasing heat flux and quality. It is not possible to determine directly whether nucleation occurs in the film.

Conventionally, the relative importance of nucleate boiling and convective evaporation are deduced from the dependence of the heat transfer coefficient on heat flux or mass flux and quality. Thome et al. (2004) showed that this could be misleading in small channels. Shiferaw et al. (2007) found that the Thome convective model, which includes cyclic dryout of the thin films round confined bubbles, provided satisfactory estimates for heat transfer in the 4.26 and $2.01 \mathrm{~mm}$ tubes of this study under conditions apparently dominated by nucleate boiling, possibly because both mechanisms involve the cyclic creation and evaporation to dryness of thin liquid films. It must be noted from the flow visualisation by Chen et al. (2006), Figure 2, and for the $0.52 \mathrm{~mm}$ tube in this paper, that the regime for which the Thome model is valid (thin, undisturbed films round discrete confined bubbles) is restricted to low
The experimental heat transfer coefficients in the $4.26-$ $1.10 \mathrm{~mm}$ tubes all exhibit at low quality "apparently nucleate boiling" characteristics, being nearly independent of quality and mass flux, if the region of heat transfer coefficient decreasing with quality, indicative of transient dryout, is excluded. For the $0.52 \mathrm{~mm}$ tube, the heat transfer coefficient is nearly independent of quality and mass flux in zone II. All these data are shown in Figure 11 on a plot of heat transfer coefficient vs. heat flux for a mass flux of $400 \mathrm{~kg} / \mathrm{m}^{2} \mathrm{~s}$ at $8 \mathrm{bar}$ pressure. The data were fitted by a power-law equation of the form $\alpha=\mathrm{Cq}^{\mathrm{n}}$, as is conventional for nucleate boiling. As mentioned above, this could be due to the fact that both mechanisms (pool and transient film evaporation) involve the cyclic creation and evaporation of thin liquid films. The exponent $\mathrm{n}$ is kept constant at 0.62 and the values of the constant $\mathrm{C}$ for the 4.26, 2.88, 2.01, 1.10 and $0.52 \mathrm{~mm}$ diameter tubes are $14.3,14.5,16.6,19.5$ and 33.7 respectively. The heat transfer coefficients for the 4.26 and $2.88 \mathrm{~mm}$ diameter tubes are almost the same; the increases for the 2.01, 1.10 and 0.52 mm tubes are 15, 35 and $134 \%$ respectively. This last figure exaggerates the benefit from decreasing diameter, because it is based on the peak values in zone I and the improvement averaged over zones I plus II is about $90 \%$. This approach may be useful for the design of cooling systems for minimum temperature difference, achieved by operating at low exit quality (avoid dryout).

The dependence of the heat transfer coefficient on mass flux and local quality is shown in Figure 12 for a heat flux of 54 (4.26-1.1 $\mathrm{mm}$ tubes) and $58 \mathrm{~kW} / \mathrm{m}^{2}(0.52 \mathrm{~mm}$ tube $)$ and 8 bar pressure. At low qualities, the approximately constant values of the heat transfer coefficient are almost independent of mass flux within the experimental uncertainty for the four larger diameter tubes. For the $4.26 \mathrm{~mm}$ tube, after $\mathrm{x}=0.15$, the heat transfer coefficient decreases slightly with mass flux, which could be related to an influence on film thickness. However, this is not repeated in the 2.88 to $1.1 \mathrm{~mm}$ tubes. As also noted earlier, further experiments are required to resolve 
the issue, using longer heated lengths to achieve larger exit qualities, subject to any limitations imposed by pressure drop. The results for the smallest diameter tube in Figure 12(e) are clearly different. There is a significant effect of mass flux in zone IV (increasing trend of heat transfer coefficient with quality). In this region, the heat transfer coefficient increases with increasing mass flux and, as seen in Figure 6(e),

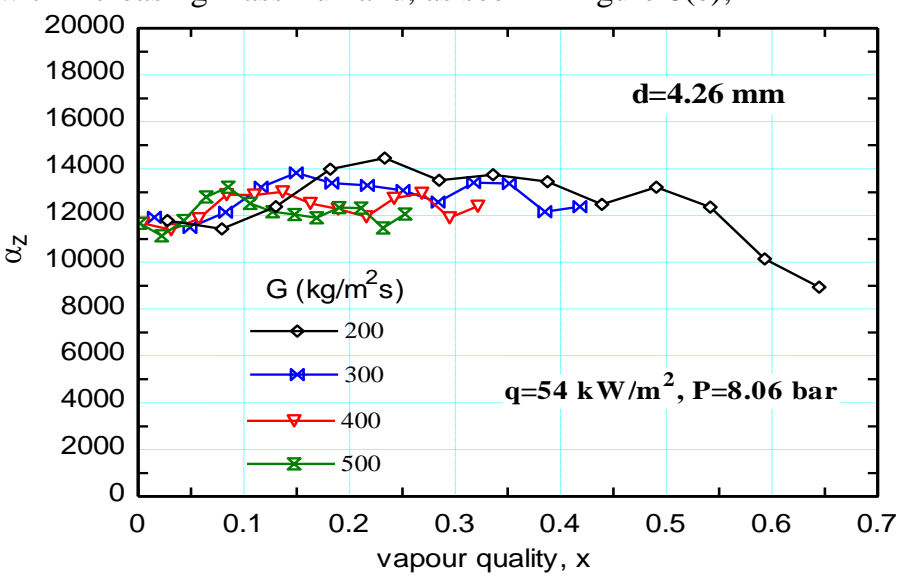

(a)

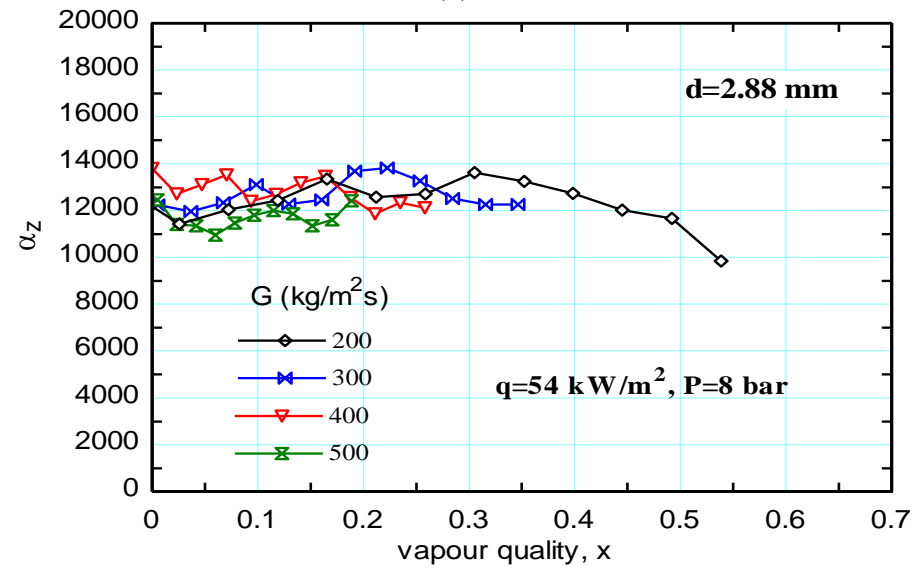

(b)

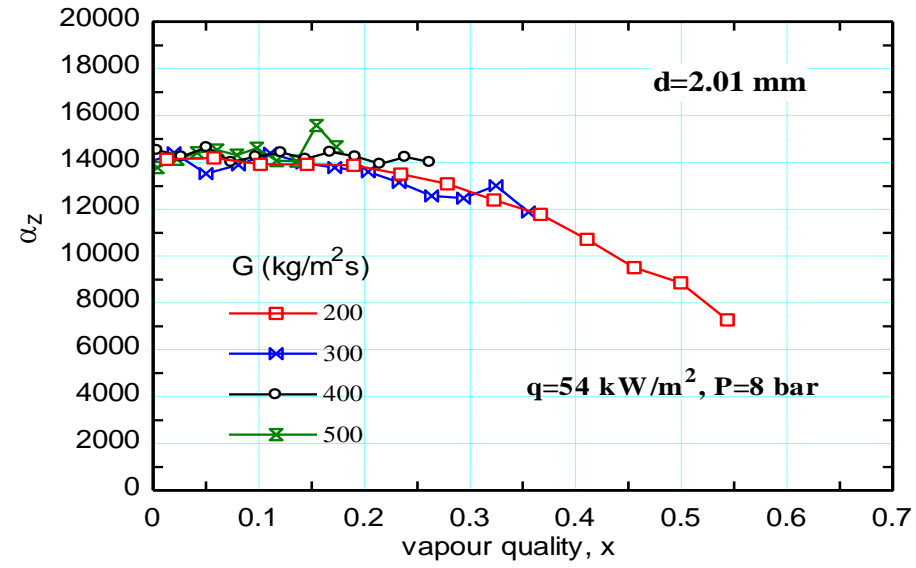

(c)

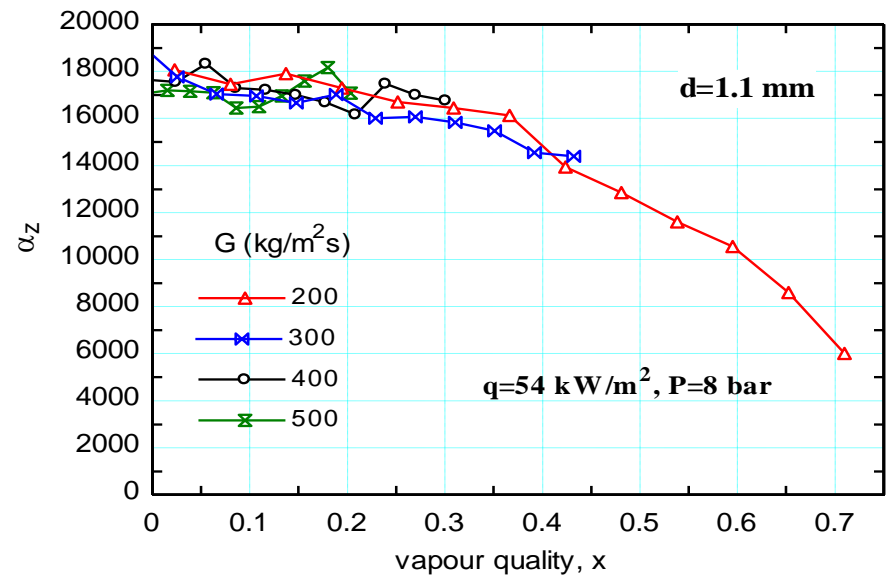

(d)

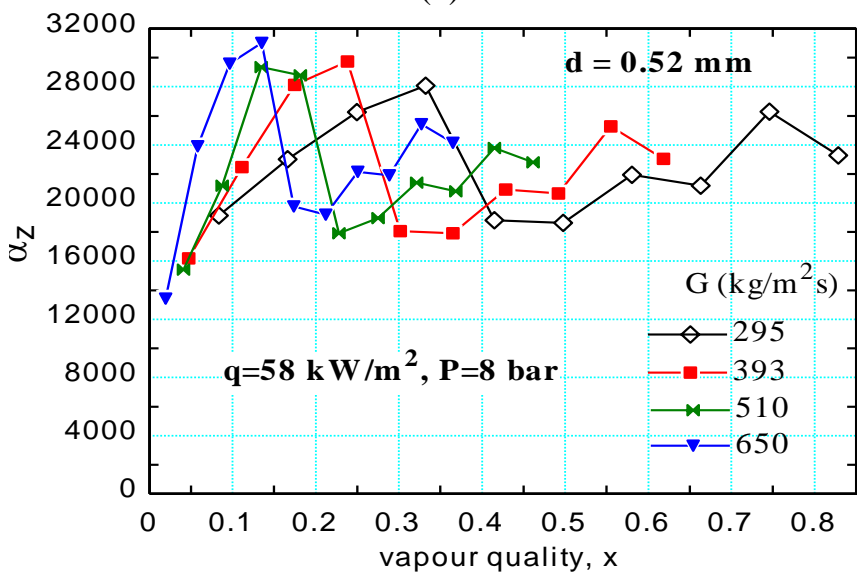

(e)

Figure 12. Effect of mass flux on heat transfer coefficient versus quality at heat flux $\left(\mathrm{q}=54\right.$ and $\left.58 \mathrm{~kW} / \mathrm{m}^{2}\right)$ and pressure (P = 8 bar): (a) $4.26 \mathrm{~mm}$; (b) $2.88 \mathrm{~mm}$; (c) $2.01 \mathrm{~mm}$; (d) $1.1 \mathrm{~mm}$; (e) $0.52 \mathrm{~mm}$.

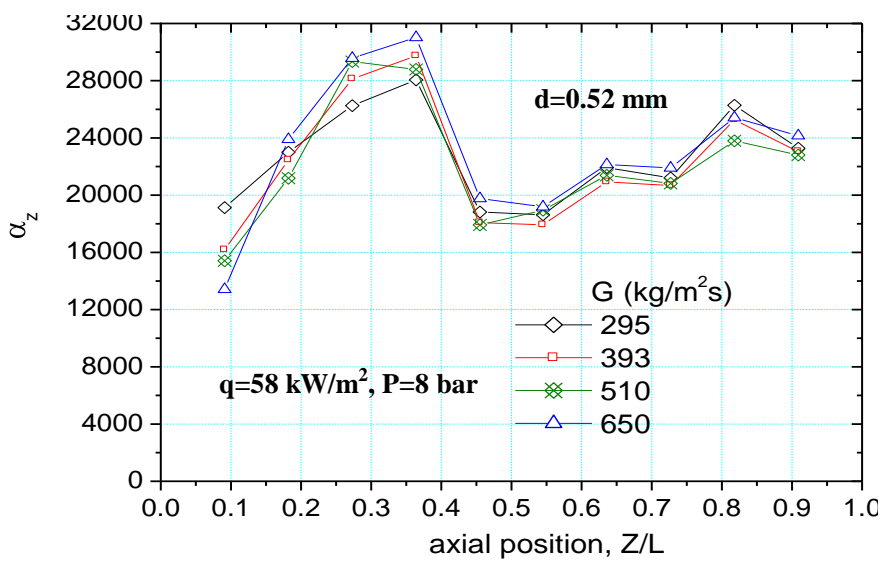




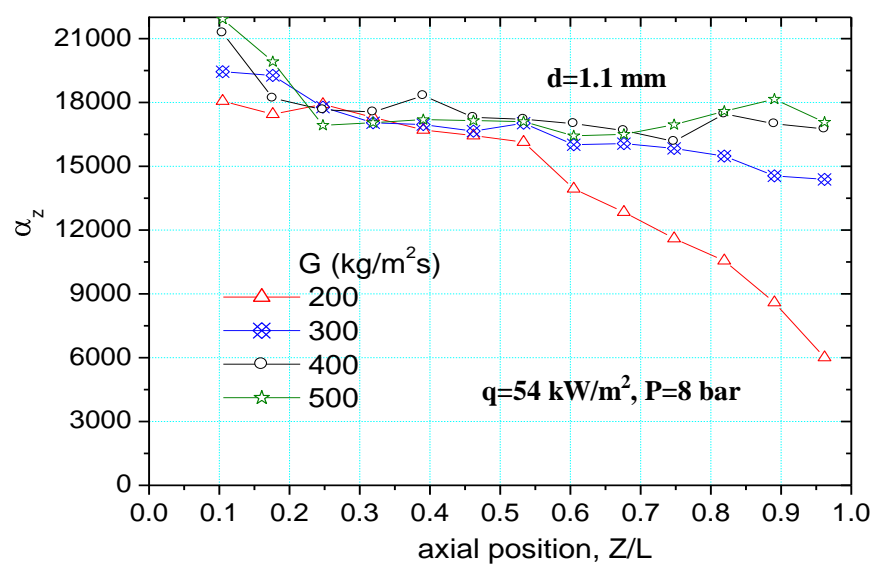

Figure 13. Effect of mass flux on heat transfer coefficient versus axial distance for heat flux $54 \mathrm{~kW} / \mathrm{m}^{2}$ in $1.1 \mathrm{~mm}$ tube and $58 \mathrm{~kW} / \mathrm{m}^{2}$ in $0.52 \mathrm{~mm}$ tube at pressure 8 bar.

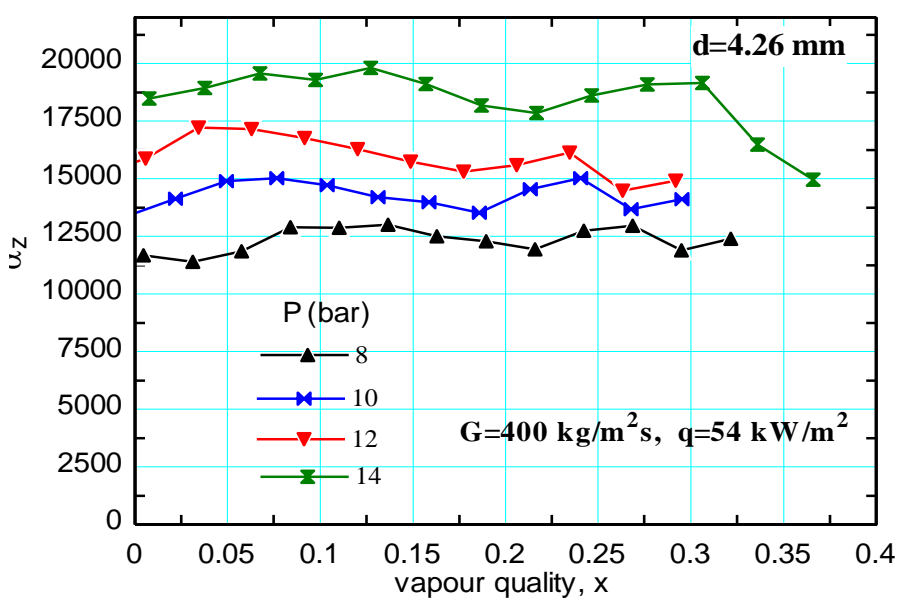

(a)

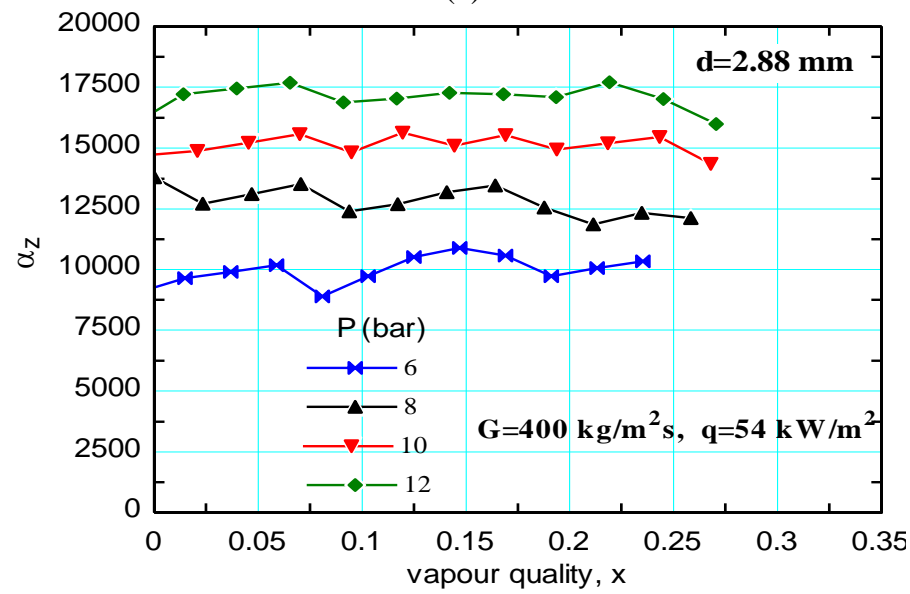

(b)

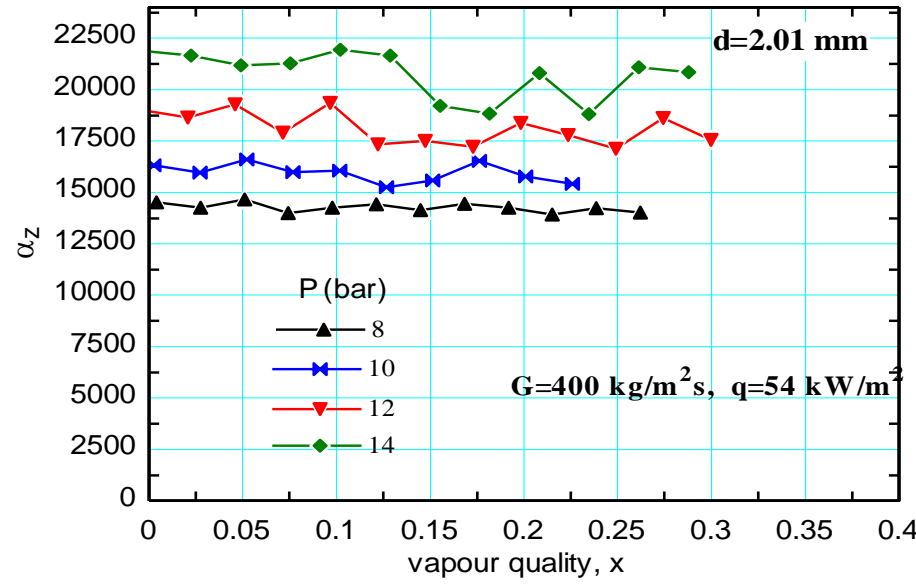

(c)

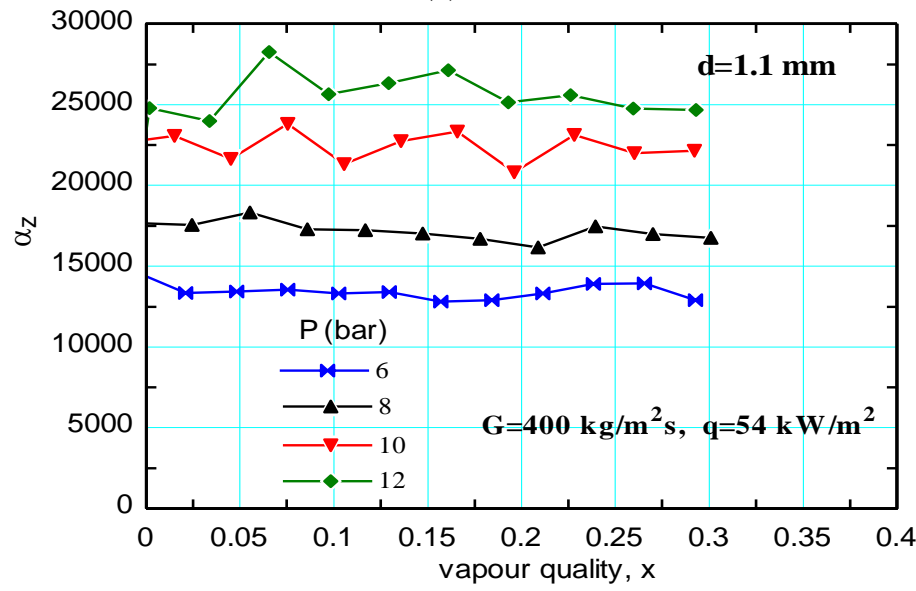

(d)

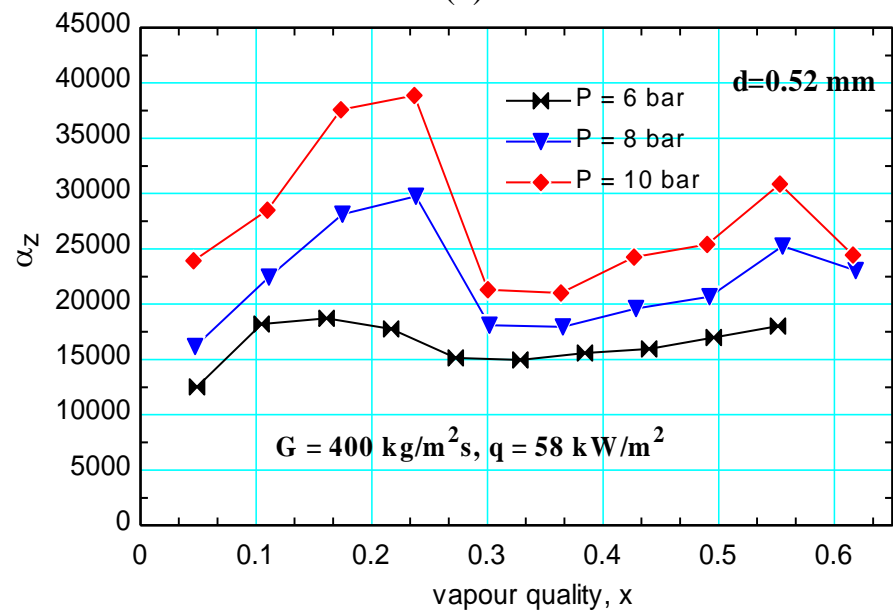

(e)

Figure 14 Effect of pressure on heat transfer coefficient vs. quality, $\mathrm{G}=400 \mathrm{~kg} / \mathrm{m}^{2} \mathrm{~s}, \mathrm{q}=54$ and $58 \mathrm{~kW} / \mathrm{m}^{2}$ : (a) $4.26 \mathrm{~mm}$; (b) $2.88 \mathrm{~mm}$; (c) $2.01 \mathrm{~mm}$; (d) $1.1 \mathrm{~mm}$; (e) $0.52 \mathrm{~mm}$

there is no obvious effect of heat flux especially at high quality. This, plus the observations at the visualization section, apparently supports the previous speculation that convective evaporation of the annular flow dominates the heat transfer mechanism at high quality, (Sumith et al (2003), Saitoh et al. (2005), Lin et al. (2001)). However, when plotted against axial distance $\mathrm{z} / \mathrm{L}$ in Figure 13, the data for the $0.52 \mathrm{~mm}$ tube collapse onto a single line independent of mass flux but with large axial variations, suggesting that timeaveraged quality is not the controlling variable. By contrast, the data for the $1.1 \mathrm{~mm}$ tube follow a line of nearly constant $\alpha$ 
at high mass flux, with lines of decreasing $\alpha$ branching off at points that move towards the tube inlet as the mass flux is reduced. It appears that quality is the relevant variable for the assumed process of transient dryout in the larger tubes of this study.

The influence of system pressure is illustrated in Figure 14 by plots of heat transfer coefficient vs. quality for all the tubes at the same mass flux of $400 \mathrm{~kg} / \mathrm{m}^{2} \mathrm{~s}$ and heat flux of $54 \mathrm{~kW} / \mathrm{m}^{2}$ $(4.26,2.88,2.01$ and $1.10 \mathrm{~mm}$ tubes $)$ and $58 \mathrm{~kW} / \mathrm{m}^{2}(0.52 \mathrm{~mm}$ tube). (These are almost the same as plots of $\alpha$ vs. z/L). For quality $\mathrm{x}<0.3$, the heat transfer coefficient increases with system pressure for the $4.26-1.10 \mathrm{~mm}$ tubes. The effect of pressure at higher qualities at various values of heat flux and mass flux were reported in Shiferaw et al. (2007). For the 4.26 $\mathrm{mm}$ diameter tube, the effect of pressure was less significant at higher qualities $(x>0.5)$, while for the $2.01 \mathrm{~mm}$ diameter tube there was a rather uniform increase in the coefficient with pressure throughout the experimental range of quality $(x<0.7)$.

Again, the $0.52 \mathrm{~mm}$ tube behaves differently, Figure 14(e). Increasing pressure causes a much larger increase in the heat transfer coefficient at small $\mathrm{x}$ in zones I and II, compared to zone IV at higher $\mathrm{x}$ and the decrease in heat transfer coefficient in zone III becomes sharper. There is a drop in heat transfer coefficient at the last measuring point for 8 and 10 bar pressure, which might indicate the onset of thin film dryout.

\section{DISCUSSION}

This paper is based on flow visualisation studies and heat transfer measurements obtained over a period of six years for five tubes of different diameters. Some of the data are new and some have been published previously. When some data sets were extended in range, the heat transfer coefficients were found to be reproducible within $\pm 5 \%$, even after intervals of 3 years. They have some features that are conventionally presented as functions of local quality, combined with features that appear to depend on the axial position within a particular test section. In the parametric studies of heat flux, mass flux and pressure in this paper, examples have been chosen from tests performed at similar times. These axial patterns are not present in singlephase tests, so they are consequences of boiling. Surface roughness has a large influence on bubble nucleation in pool boiling, so axial variations in surface roughness may influence local nucleation. The influence of surface conditions on boiling in small metal tubes has as yet received little attention. It may also affect a parameter in the convective boiling model of Thome et al. (2004), the minimum stable thickness of the evaporating liquid film round confined bubbles. Shiferaw et al.(2007) showed that the predictions of the Thome et al. model were improved if the experimental measurements of roughness were used instead of the recommended film thickness. The surface roughness of samples from the four larger tubes used in this study were measured after sectioning by scanning in an axial direction with a conventional contact stylus, values given in Table 1. The surface roughness of the $0.52 \mathrm{~mm}$ tube was obtained from a 3-D sample, captured using a high-resolution non-contact probe.

In the experiments described here, including those performed earlier by Chen et al. (2006), flow patters were observed at the exit of the test section. Observations within a tube are possible for transparent tubes with transparent thinfilm heaters, as in the experiments of Owhaib et al. (2004), but the nucleation characteristics are different and it is difficult to obtain simultaneous accurate measurements of the wall temperature. The flow patterns observed at the exit from the $0.52 \mathrm{~mm}$ tube were certainly different from those observed earlier in the relatively larger diameter tubes (4.26 -1.1 mm) by Chen et al. (2006). These differences include the absence of dispersed bubble flow and the appearance of ring flow. Thus, there were further differences between the flow patterns leaving the 2.88 and $4.26 \mathrm{~mm}$ diameter tubes and those from the 2.01 and $1.1 \mathrm{~mm}$ tubes, which exhibited confined flow, slimmer vapour slugs, thinner liquid films, and smoother vapour-liquid interfaces. These differences coincided with the progressive transition to higher heat transfer coefficients in the 2.01 and $1.10 \mathrm{~mm}$ tubes. Using the confinement number (Cornwell and Kew 1993), the deviation from large tube characteristics should be observed at diameters of 1.4 to 1.7 $\mathrm{mm}$ at $6-14$ bar pressure for R134a, which is roughly in agreement with the present heat transfer results and flow visualization observations. "Small tube characteristics" in 1.1 mm tubes were reported in the previous studies of Damianides and Westwater (1988) and Mishima and Hibiki (1996).

Flow maps such as Figure 2, based on observations at the exit from the $4.26-1.10 \mathrm{~mm}$ tubes, show that, at the low mass fluxes covered in the present heat transfer tests, the transition to annular flow shifts to higher qualities approaching $\mathrm{x} \sim 0.5$. While the information on flow regimes cannot be transferred with certainty to upstream locations, it is likely that slug/churn flow is the typical flow pattern in the region of near-uniform high heat transfer coefficient dependent primarily on heat flux. This could be at least one of the reasons for the increase in the heat transfer coefficient with a reduction in the channel size. The relative importance of nucleate and convective boiling in this region is still unclear. However, there are claims that suggest that, for small passages, the same behaviour, i.e. uniform heat transfer coefficient dependent on heat flux and independent of quality can be explained if transient evaporation of the thin liquid film surrounding elongated bubbles, without nucleate boiling contribution, is the dominant heat transfer mechanism, Thome et al. (2004). One may argue, that the variations in heat transfer coefficient with axial position, evident in Figure 6, especially for the larger tubes, may indicate some dependence on nucleate boiling. Kenning and Yan (2003) observed cyclic triggering of nucleate boiling in smooth films round confined bubbles in water associated with pressure fluctuations. This needs further investigation.

The heat transfer results of the smallest diameter tube $(0.52 \mathrm{~mm})$ demonstrated different characteristic than the rest of the tubes, particularly at the high quality region. It is the only tube for which the incoming liquid flow is laminar and this may influence the initiation of confined bubble (slug) flow. Unlike the larger tubes that were examined in this study, which exhibit dryout phenomena at high quality as the heat flux increases with a drop of the heat transfer coefficient with quality, a monotonic increase in heat transfer coefficient was observed near the exit for the smallest diameter tube. This could be related to laminar flow and domination of surface tension force over momentum, providing more uniform liquid 
film thickness along the circumference, with less interfacial waves and disturbances, which improve wetting of the wall, Shiferaw et al. (2008). In addition, the dependence of the heat transfer coefficient on axial position is much stronger in the $0.52 \mathrm{~mm}$ tube, Figure 13, extending to high quality in the annular flow regime.

These observations indicate additional changes as the size diminishes further into microscales. In general, the complex dependence of the heat transfer rate on various parameters suggest, the difficulty of interpreting the heat transfer mechanisms using simple conventional terms and the challenge of heat transfer modelling.

\section{CONCLUSIONS}

Flow boiling patterns and heat transfer results with R134a and five tubes of diameter 4.26, 2.88, 2.01, 1.10 and $0.52 \mathrm{~mm}$ were presented in this paper. It was anticipated that the wide range of data at different diameters could be used to identify the threshold(s), where the small or micro diameter effects become significant. The major conclusions that can be drawn from the current part of this long term study are as follows:

1. In the 4.26 and $2.88 \mathrm{~mm}$ diameter tubes, the heat transfer coefficient increases with heat flux and system pressure, but did not change with vapour quality when the quality was less than about $40 \%$ to $50 \%$, for low heat flux. The boundary moves to $20 \%-30 \%$ for the 2.01 and $1.10 \mathrm{~mm}$ diameter tubes. The actual quality values depends also on the heat flux. In this region, there is no significant difference in the magnitude of the heat transfer coefficient of the 4.26 and $2.88 \mathrm{~mm}$ tubes. However, there is an increase of $15 \%$ and $35 \%$ when the tube diameter is reduced to 2.01 and $1.10 \mathrm{~mm}$ respectively.

2. The heat transfer coefficient behaviour of the tubes (4.26$1.1 \mathrm{~mm}$ ) at low quality could be interpreted as the evidence that nucleate boiling is the dominant heat transfer mechanism. However, transient evaporation of the thin liquid film surrounding elongated bubbles, which is a dominant flow pattern in small passages, without a nucleate boiling contribution, may also result in the same heat transfer coefficient dependence. For higher vapour qualities, the heat transfer coefficient becomes independent of heat flux and decreases with vapour quality. This could be caused by partial (intermittent) dryout, in the convection dominated region. This leads to the design recommendation that exit qualities be kept low, Zhang (2004).

3. The heat transfer results are consistent with the observations of Chen et al. (2006), who concluded that flow patterns for the 4.26 and $2.88 \mathrm{~mm}$ diameter tubes exhibit flow pattern characteristics similar to "normal" diameter tubes, while "small tube characteristics", e.g. the appearance of confined flow, were observed when the tube diameter was reduced to $2.01 \mathrm{~mm}$ and further to $1.10 \mathrm{~mm}$.

4. In general, the results confirm that a tube diameter of roughly $2 \mathrm{~mm}$ can be considered as a critical diameter to distinguish conventional and small diameter tubes for $\mathrm{R} 134 \mathrm{a}$ at the test conditions covered in the study.

5. As the tube diameter decreased further down to $0.52 \mathrm{~mm}$, different flow and heat transfer characteristics were observed indicating a possible further change as the size diminishes. These include: (a) The flow patterns observed in the $0.52 \mathrm{~mm}$ tube are different, i.e. absence of dispersed bubble flow, diminishing appearance of churn flow and appearance of liquid-ring flow regime, which becomes more prominent in this tube.

(b) The dependence of the heat transfer coefficient on quality, heat flux and mass flux change sharply in character at a threshold value of heat flux. In the low heat flux region, there is no significant effect of heat flux but the heat transfer coefficient decreases (at low mass flux and pressure) or remains constant (at higher mass flux and pressure), then increases gradually with quality. At moderate and high heat flux, in the front part of the channel, the heat transfer coefficient increases with increasing heat flux and reaches a maximum at an intermediate quality which might be caused by transient partial dryout or dry patches in the confined bubble regime. At higher quality, towards the test section exit, the heat transfer coefficient gradually increases again with quality but there is no clear effect of heat flux. The heat transfer coefficient increases with mass flux in this region. According to the conventional interpretation, this is evidence for a convective boiling dominant heat transfer mechanism in the annular flow region. Increase in the heat transfer coefficient in the region where it is independent of quality is $134 \%$ compared to the $4.26 \mathrm{~mm}$ tube.

The results indicate the complexity of interpreting heat transfer characteristics and understanding the prevailing mechanisms, and consequently, the difficulty with the development of generalised models. Phenomenological models that are based on the local flow structure could be developed for clearly specified ranges. Therefore, it is important to identify the range of applicability of dominant flow regimes. Currents results also indicate that further research is needed for clarification and better understanding of the different characteristics associated with microtubes and channels

\section{Acknowledgement}

The authors wish to thank Prof Andrea Luke of Hannover University and her team, who carried out the surface roughness measurements for the $0.52 \mathrm{~mm}$ tube, and to acknowledge the contributions of Drs Y.S. Tian, L. Chen and $\mathrm{X}$. Huo to the earlier part of this long term study.

\section{NOMENCLATURE}

Bo Boiling number, $q^{\prime \prime} / G \cdot h_{l v}$

Ë̈ Etvos number, $g\left(\rho_{l}-\rho_{g}\right) d^{2} / \sigma$

Co Confinement number, $\quad \mathbf{F} / g\left(\rho_{l}-\rho_{v}\right)^{\text {Tp }} / d$

$d \quad$ diameter, $m$

G mass flux, $\mathrm{kg} / \mathrm{m}^{2} \mathrm{~s}$ 


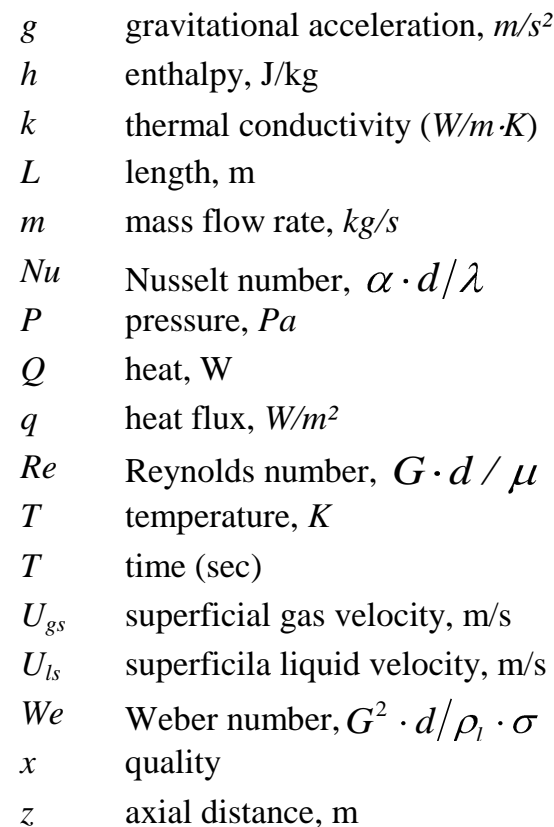

\section{GREEK SYMBOLS}

$\begin{array}{ll}\alpha & \text { heat transfer coefficient, } W /\left(m^{2} K\right) \\ \Delta & \text { finite increment } \\ \rho & \text { density, } \mathrm{kg} / \mathrm{m}^{3} \\ \sigma & \text { surface tension, } \mathrm{N} / \mathrm{m}\end{array}$

\section{SUBSCRIPTS}

$\begin{array}{ll}h & \text { hydraulic } \\ i & \text { index, internal } \\ l & \text { liquid } \\ l o & \text { liquid only } \\ o & \text { outer } \\ s p & \text { single phase } \\ t p & \text { two phase } \\ v & \text { vapour } \\ w & \text { wall } \\ w i & \text { inner wall } \\ w o & \text { outer wall } \\ 0 & \text { initial }\end{array}$

\section{REFERENCES}

Adams, T.M., Abdel-khalik S.I., Jeter S.M. and Qureshi Z.H., 1998, An Experimental Investigation of Single-Phase Forced Convection in Micro-Channels, Int. J. Heat Mass Transfer, Vol.41, No. 6-7, pp. 851-857.

Agostini, B., Thome, J.R., 2005, Comparison of an extended database of flow boiling heat transfer coefficient in multimicrochannel elements with the three-zone model, in: ECI International Conference on Heat Transfer and Fluid Flow in Microscale, Castelvecchio Pascoli, Italy.

Baird, J. R., Bao, Z.Y., Fletcher, D.F., Haynes, B.S., 2000, Local flow boiling heat transfer coefficients in narrow conduits. In: Bar-Cohen A (ed) Boiling: phenomena and engineering applications, Anchorage, Alaska, Vol. 2, pp. 447-466.

Barnea, D., Luninski, Y., Taitel, Y., 1983, Flow pattern in horizontal and vertical two phase flow in small diameter pipes,
The Canadian Journal of Chemical Engineering, Vol. 61, No. 5, pp. 617-620.

Bao, Z. Y., Fletcher, D.F., Haynes, B.S., 2000, Flow boiling heat transfer of Freon R11 and HCFC123 in narrow passages, Int. J. Heat Mass Transfer, Vol. 43, pp. 3347-3358.

Blasius, H., 1913, Forschungshaft, VDI-Heft 131 (1).

Brauner, N. and Moalem-Maron, D., 1992, Identification of the range of small diameter conduits, regarding two-phase flow pattern transitions, Int. Comm. Heat Mass Transfer, Vol. 19, pp. 29-39.

Brereton, G.J., Crilly, R.J., Spears, J.R., 1998, Nucleation in small capillary tubes. Chem. Phys. 230, 253-265.

Carey V. P., Tervo, P., Shullenberger, K., 1992, Partial dryout in enhanced evaporator tubes and its impact on heat transfer performance, SAE Technical Paper 920551.

Chen, L., Tian, Y.S., Karayiannis, T.G., 2006, The effect of tube diameter on vertical two-phase flow regimes in small tubes, Int. J. Heat Mass Transfer, 49, 4220-4230.

Choi, S.B. Barron, R.F. and Warrington, R.O., 1991, Fluid flow and heat transfer in microtubes, Micromechanical Sensors, Actuators and Systems, ASME DSC, Vol. 32, pp. 123-128.

Cornwell, P. A. K. and Kew, P. A., 1993, Boiling in small parallel channels. In Energy Efficiency in Process Technology, Edited by P. A. Pilavachi. Elsevier Applied Science, London, pp. 624638.

Damianides, D. A. and Westwater, J.W., 1988, Two-phase flow patterns in a compact heat exchanger and in small tubes, Second UK National Conference on Heat Transfer, Volume 11 Sessions 4A-6C, pp. 1257-1268.

D1'az, M. C., Schmidt, J., 2007, Experimental investigation of transient boiling heat transfer in microchannels, Int. Journal of Heat and Fluid Flow (28) 95-102.

Dittus, F.W. and Boelter L.M.K., 1930, Heat transfer in automobile radiators of tubular type, Univ. California Berkeley, Publ. Eng. 2/13, pp. 443-461.

Dupont, V., Thome, J. R., Jacobi, A.M., 2004, Heat transfer model for evaporation in microchannels., Part II: comparison with the database, Int. J. Heat and Mass Transfer, Vol. 47, pp. 3387-3401.

Dupont, D., J.R. Thome, 2004, Evaporation in microchannels: influence of the channel diameter on heat transfer, Journal of Microfluidics and Nanofluidics, 119-125.

Fujita, Y., Yang, Y., Nami, F., 2002, Flow boiling heat transfer and pressure drop in uniformly heated small tubes, in: Proc. $12^{\text {th }}$ Int. Heat Transfer Conf., Grenoble, 3, pp. 743-748. Gnielinski, V., 1997, VDI-Wärmeatlas 1997, SpringerVerlag, Berlin, Heidelberg.

Hapke, I., Boye, H., Schmidt, J., 2000. Onset of nucleate boiling in minichannels. Int. J. Therm. Sci. 39, 505-513.

Huo, X., Tian, Y.S., Karayiannis, T.G., 2007, R134a Flow boiling heat transfer in small diameter tubes, Advances in compact heat exchangers, R.T. Edwards, Inc. chapter 5, pp 95-111.

Kandlikar, S. G., Grande, W.J., 2003, Evolution of microchannel flow passages-Thermohydraulic performance 
and fabrication technology, Heat Transfer Engineering, 25 (1), 3-17.

Kawahara, A., Chung, P.M.-Y., Kawaji, M., 2002, Investigation of two-phase flow patterns, void fraction and pressure drop in a micro-channel, Int. J. Multiphase Flow, Vol. 28, pp. 1411-1435.

Kenning, D.B.R. and Yan, Y., 2001, Saturated flow boiling of water in a narrow channel: experimental investigation of local phenomena, IChemE Trans. A, Chem. Eng. Res. and Design $79,425-436$.

Kenning, D. B. R., Wen, D.S., Das, K.S., Wilson, S.K., 2006, Confined growth of a vapour bubble in a capillary tube at initially uniform superheat: experiments and modelling, Int. J. Heat Mass Transfer, 49, 4653-4671.

Kew, P. A., Cornwell, K., 1997, Correlations for the prediction of boiling heat transfer in small diameter channels, Applied Thermal Eng., 17 (8-10) 705-715.

Kew P. A., Cornwell, K., 1996, On pressure fluctuations during boiling in narrow channels, $2^{\text {nd }}$ European Thermal-Science and $14^{\text {th }}$ UIT National Heat Transfer Conference, Rome, 1323 1327.

Khodabandeh, R., 2003, Influence of channel diameter on boiling heat transfer in a closed advanced two-phase thermosiphon loop. Proceedings of the 5th international boiling conference Montego Bay, Jamaica.

Kuznetsov, V. V., Shamirzaev, A.S., 1999, Two phase flow pattern and flow boiling heat transfer in non-circular channel with a small gap, Two-Phase Flow Modelling and Experimentation, Pisa, pp. 249-253.

Kuwahara, K., Koyama, S., Hashimoto, Y., 2000, Characteristics of evaporation heat transfer and flow pattern of pure refrigerant HFC134a in a horizontal capillary tube, in: Proceeding of the 4th JSME-KSME Thermal Engineering Conference, pp. 385-390.

Lazarek, G. M., Black, S.H., 1982, Evaporative heat transfer, pressure drop and critical heat flux in a small vertical tube with R-113, Int. J. Heat Mass Transfer, 25 (7) 945-960.

Lee, H. J., Lee, S.Y., 2001, Heat transfer correlation for boiling flows in small rectangular horizontal channels with low aspect ratios, Int. J. Multiphase Flow, 27, 2043-2062.

Lie, Y.M., Su, F.Q., Lai, R.L., Lin, T.F., 2006, Experimental study of evaporation heat transfer characteristics of refrigerants $\mathrm{R}-134 \mathrm{a}$ and R-407C in horizontal small tubes, IJHMT (49) 207-218.

Lin, S., Kew, P.A., and Cornwell, K., 1998, Two-phase flow regimes and heat transfer in small tubes and channels, Heat Transfer1998, Proceedings of 11th IHTC, Vol. 2, August 2328, Kyongju, Korea, pp. 45-50.

Lin, S., Kew, P.A., Cornwell, K., 2001, Two-phase heat transfer to a refrigerant in a $1 \mathrm{~mm}$ diameter tube, Int. J. Ref. 24, 51-56.

Mehendale, S. S., Jacobi, A. M., Shah, R. K., 2000, Fluid Flow and Heat Transfer at Micro- and Meso-Scales with Application to Heat Exchanger Design, Applied Mechanics Reviews, Vol. 53, no. 7, pp. 175-193.

Mishima, K. and Hibiki, T., 1996, Some characteristics of airwater two-phase flow in small diameter vertical tubes, Int. J. Multiphase flow, Vol. 22, No. 4, pp. 703-712,.
Oh, H. K., Katsuta, M., Shibata, K., 1998, Heat transfer characterstics of R134a in a capillary tube heat exchanger, in:Proceedings of $11^{\text {th }}$ IHTC, Vol. 6, pp. 131-136.

Owhaib, W, Palm B., 2003, Flow boiling heat transfer in a vertical circular microchannel tube. Eurotherm seminar, Valencia, Spain, no. 72.

Owhaib, W., Martin-Callizo, C., Palm, B., 2004, Evaporative heat transfer in vertical circular microchannels, Appl. Thermal Eng. 24, 1241-1253.

Qu, W., Mudawar, I., 2003, Flow boiling heat transfer in two phase microchannel heat sinks. I. Experimental investigation and assessment of correlation methods, Int. J. Heat Mass Transfer, 46, 2755-2771.

Peng, X.F., Wang, B.-X., 1993. Forced convection and flow boiling heat transfer for liquid flowing through microchannels. Int. J. Heat Mass Transfer 26, 3421-3427.

Peng, X. F., Hu, H. Y., Wang, B. X., 1998, Boiling Nucleation During Liquid Flow in Microchannels, Int .J. Heat Mass Transfer, (41) pp. 101-106.

Petukhov, B. S., 1970, Heat transfer and friction in turbulent pipe flow with variable physical properties, In Advances in Heat Transfer Vol. 6, Academic Press, New York, pp. 503564.

Revellin, R., Dupont, V., Ursenbacher, T. Thome, J. R., Zun, I., 2006, Characterization of diabatic two-phase flows in microchannels: Flow parameter results for R-134a in a 0.5 mm channel, Int. J. Multiphase Flow (32) 755-774.

Revellin, R., Thome, J.R., 2007, A new type of diabatic flow pattern map for boiling heat transfer in microchannels, J. Micromech. Microeng. 17, 788-796

Saitoh, S., Daiguji, H., Hihara, E., 2005, Effect of tube diameter on boiling heat transfer of R134a in horizontal small diameter tubes, Int. J. Heat Mass Transfer, 48, 4973-4984.

Shiferaw, D., Huo, X., Karayiannis, T.G., Kenning, D.B.R., 2007, Examination of heat transfer correlations and a model for flow boiling of R134a in small diameter tubes, Int. J Heat Mass Transfer, Vol. 50, pp. 5177-519350.

Shiferaw, D., Karayiannis, T.G. and Kenning, D.B.R. Flow boiling in a $1.1 \mathrm{~mm}$ vertical tube with R134a: Experimental Results and comparison with model, Int. Journal of Thermal Sciences, In press 2008.

Shiferaw, D., Mahmoud, M.M., Karayiannis, T.G. and Kenning, D.B.R., 2008, Experimental flow boiling study in a $0.52 \mathrm{~mm}$ diameter vertical tube using R134a, $5^{\text {th }}$ European Thermal-Sciences Conference 18-22 May 2008, Eindhoven, the Netherlands.

Serizawa, A., Feng, Z., Kawara, Z., 2002, Two phase flow in microchannels, Exp. Thermal Fluid Sc., Vol. 26, pp. 703-714

Sumith, B., Kaminaga, F., Matsumura, K., 2003, Saturated flow boiling of water in a vertical small diameter tube, Exp. Therm. Fluid Sci. 27, 789-801.

Thome, J. R., 2004, Boiling in microchannels: a review of experiment and theory, Int. J. Heat Fluid Flow, 25, 128-139.

Thome, J.R., Dupont, V., Jacobi, A.M, 2004, Heat transfer model for evaporation in microchannels, Part I: presentation of the model, Int. J. Heat Mass Transfer, Vol. 47, pp. 33753385 . 
Tran, T. N., Wambsganss, M.W., France, D.M., 1996, Small circular- and rectangular-channel boiling with two refrigerants, Int. J. Multiphase Flow, Vol. 22, no. 3, pp. 485-498.

Wambsganss, M. W., France, D.M., Jendraejczyk, J.A., Tran, T.N., 1993, Boiling heat transfer in a horizontal small-diameter tube, Journal of Heat Transfer, 115, 963-972.

Wen, D. S., Kenning, D.B.R., Yan, Y., 2002, Flow boiling of water in a narrow vertical channel at low mass flux: observations of local phenomena, Proc. $12^{\text {th }}$ International Heat Transfer Conference, Grenoble, 3, 773-778.

Xiong, R. and Chung, J. N., 2007, An experimental study of the size effect on adiabatic gas-liquid two-phase flow patterns and void fraction in microchannels, Physics of Fluids, Vol. 19.

Xu, J., Shen, S., Gan, Y., Li, Y., Zhang, W., Su, Q., 2005. Transient flow pattern based microscale boiling heat transfer mechanisms. Journal of Micromechanics and Microengineering 15, 1344-1361.

Yan, Y., Kenning, D.B.R., 1998, Pressure and temperature fluctuations during boiling in narrow channel, Eurotherm 62: Heat Transfer in Condensation and Evaporation, Grenoble, 107-1223.
Yan, Y. Y., Lin, T.F, 1998, Evaporation heat transfer and pressure drop of refrigerant R-134a in a small pipe, Int. J. Heat Mass Transfer, 41, 4183-4194.

Yen, T., Kasagi, N., Suzuki, Y., 2003, Forced convective boiling heat transfer in microtubes at low mass and heat fluxes Int. J. Multiphase Flow (29) 1771-1792.

Yu, W., France, D.M., Wambsganss, M.W., Hull, J.R., 2002, Two-phase pressure drop, boiling heat transfer, and critical heat flux to water in a small diameter horizontal tube, Int. J. Multiphase Flow, Vol. 28, pp. 927-941.

Zhang, L., Goodson, K.E. and Kenny, T.W., 2004, Silicon microchannel heat sinks, theories and phenomena, chap. 5-7, Springer, Berlin.

Zhang, L., Wang, E.N., Goodson, K.E., Kenny, T.W., 2005, Phase change phenomena in silicon microchannels, Int. J. Heat Mass Transfer, 48 1572-1582

Zhang, L., Koo, J., Jiang, L., Goodson, K.E., Santiago, J.G., Kenny, T.W., 2001, Study of boiling regimes and transient signal measurements in microchannels, in: Proc.

Transducers'01, Munich, Germany, pp. 1514-1517. 